IZA DP No. 6613

The Impact of Family Income on Child Achievement: Evidence from the Earned Income Tax Credit

Gordon B. Dahl

Lance Lochner

May 2012 


\title{
The Impact of Family Income on Child Achievement: Evidence from the Earned Income Tax Credit
}

\author{
Gordon B. Dahl \\ University of California, San Diego, \\ NBER and IZA \\ Lance Lochner \\ University of Western Ontario \\ and NBER \\ Discussion Paper No. 6613 \\ May 2012 \\ IZA \\ P.O. Box 7240 \\ 53072 Bonn \\ Germany \\ Phone: +49-228-3894-0 \\ Fax: +49-228-3894-180 \\ E-mail: iza@iza.org
}

\begin{abstract}
Any opinions expressed here are those of the author(s) and not those of IZA. Research published in this series may include views on policy, but the institute itself takes no institutional policy positions.

The Institute for the Study of Labor (IZA) in Bonn is a local and virtual international research center and a place of communication between science, politics and business. IZA is an independent nonprofit organization supported by Deutsche Post Foundation. The center is associated with the University of Bonn and offers a stimulating research environment through its international network, workshops and conferences, data service, project support, research visits and doctoral program. IZA engages in (i) original and internationally competitive research in all fields of labor economics, (ii) development of policy concepts, and (iii) dissemination of research results and concepts to the interested public.
\end{abstract}

IZA Discussion Papers often represent preliminary work and are circulated to encourage discussion. Citation of such a paper should account for its provisional character. A revised version may be available directly from the author. 


\title{
ABSTRACT \\ The Impact of Family Income on Child Achievement: Evidence from the Earned Income Tax Credit ${ }^{*}$
}

\begin{abstract}
Past estimates of the effect of family income on child development have often been plagued by endogeneity and measurement error. In this paper, we use an instrumental variables strategy to estimate the causal effect of income on children's math and reading achievement. Our identification derives from the large, non-linear changes in the Earned Income Tax Credit (EITC) over the last two decades. The largest of these changes increased family income by as much as $20 \%$, or approximately $\$ 2,100$, between 1993 and 1997 . Using a panel of roughly 4,500 children matched to their mothers from National Longitudinal Survey of Youth datasets allows us to address problems associated with unobserved heterogeneity, endogenous transitory income shocks, and measurement error in income. Our baseline estimates imply that a $\$ 1,000$ increase in income raises combined math and reading test scores by $6 \%$ of a standard deviation in the short-run. Test gains are larger for children from disadvantaged families and are robust to a variety of alternative specifications.
\end{abstract}

JEL Classification: I2, I3

Keywords: family income, poverty, educational achievement

Corresponding author:

Gordon B. Dahl

Department of Economics

University of California, San Diego

9500 Gilman Drive \#0508

La Jolla, CA 92093-0508

USA

E-mail: gdahl@ucsd.edu

\footnotetext{
*We thank Mark Bils, Dan Black, David Blau, Julie Cullen, David Dahl, Greg Duncan, Rick Hanushek, Shakeeb Khan, Robert Moffitt, Krishna Pendakur, Uta Schoenberg, Todd Stinebrickner, Chris Taber, Mo Xiao and three anonymous referees for helpful comments. We also thank seminar participants at University of Arizona, Brigham Young University, UC Berkeley, Case Western GSB, University of Chicago GSB, Institute for Fiscal Studies, Federal Reserve Bank of Cleveland, University of Illinois, University of Kentucky, London School of Economics, Michigan State, Northwestern University, Stanford University GSB, University of Toronto, University of Waterloo, and Wilfred Laurier University, and conference participants at the 2005 Institute for Research on Poverty Summer Workshop, 2005 Canadian Econometrics Study Group Meeting, 2005 NBER Summer Institute, 2008 RCEA Labor Workshop. Philippe Belley, Eda Bozkurt, Javier Cano Urbina, Marina Renzo, and Fernando Leiva provided excellent research assistance. Both authors gratefully acknowledge financial support from the William T. Grant Foundation. Lochner also acknowledges support from the Social Sciences and Humanities Research Council of Canada.
} 


\section{Introduction}

In 2008, 13.2 million children in the U.S. under the age of 18, or more than one in six children, were living in poverty (U.S. Census Bureau, 2009). Given such a high poverty rate, the consequences of growing up poor on child well-being and future success has emerged as an important research topic. Of particular interest is whether income support programs like the Earned Income Tax Credit (EITC) can improve child development. However, the extent to which income maintenance programs, and family income more generally, impact children is not easily estimated.

The major challenge faced by researchers attempting to estimate the causal effect of family income on children's outcomes has been the endogeneity of income. Children growing up in poor families are likely to have adverse home environments or face other challenges which would continue to affect their development even if family income were to increase substantially. Furthermore, yearto-year changes in family circumstances like parental job loss or promotion, illness, or moving to a new neighborhood may affect both family income as well as family dynamics and parenting behavior. The latter poses a problem for traditional empirical studies that fail to separately identify the effects caused by changes in income from the effects of changes in other unmeasured family circumstances. These concerns have long prevented the literature from reaching a consensus on whether family income has a causal effect on child development (see Duncan and Brooks-Gunn (1997), Haveman and Wolfe (1995), Mayer (1997)).

Since the mid-1990s, one of the largest federal anti-poverty programs in the U.S. has been the EITC, which provides cash assistance to low-income families and individuals who have earnings from work. ${ }^{1}$ Low income families with two or more children can receive a credit of up to $40 \%$ of their income in recent years (up to $\$ 4,824$ in 2008), while families with one child can receive a credit of up to $34 \%$. In 2007 , the EITC provided $\$ 48.7$ billion in income benefits to 25 million families and individuals, lifting more children out of poverty than any other government program (Center on Budget and Policy Priorities, 2009). It is natural to ask what effect the EITC and other income maintenance programs have on disadvantaged children.

Expansions of the EITC in the late 1980s and 1990s provide an exogenous source of income variation for American families that we use to identify the effects of family income on child achievement. Figure 1 shows that EITC expansions over this period were sizeable and primarily benefitted low to middle income families. Not only did the maximum benefit amount increase substantially,

\footnotetext{
${ }^{1}$ See Hotz and Scholz (2003) and Eissa and Hoynes (2005) for detailed descriptions of the EITC program and a summary of related research.
} 
but the range of family income which qualified families for EITC benefits also expanded. The figure shows that two-child families with pre-tax incomes ranging from $\$ 12,000-16,000$ would have seen their EITC payments increase by as much as $\$ 900$ from 1987 to 1993 and another $\$ 2,100$ between 1993 and $1997 .^{2}$ The maximum subsidy rate for low income families with two children doubled from $19.5 \%$ to $40 \%$ of earned income over the latter period. Expansions for single-child families were quite similar to those for two-child families prior to 1993; however, they have been more modest since.

We estimate the impact of changes in family income (resulting from the EITC expansions) on child cognitive achievement. Our estimation strategy is based on the fact that low to middle income families benefitted substantially from expansions of the EITC in the late-1980s and mid-1990s while higher income families did not. To the extent that income affects child achievement, we should observe relative improvements in the test scores of children from families benefitting the most from the EITC expansions.

Our analysis uses panel data on almost 4,500 children matched to their mothers in the Children of the National Longitudinal Survey of Youth (NLSY). These data contain a rich set of income and demographic measures. More importantly, these data have up to five repeated measures of cognitive test scores per child taken every other year, which allows us to account for unobserved child fixed effects.

Our instrumental variables estimates suggest that current income has a significant effect on a child's math and reading achievement - a $\$ 1,000$ increase in family income raises math and reading test scores by about $6 \%$ of a standard deviation. The estimated effects are larger for children from more disadvantaged backgrounds, for younger children, and for boys. Simple dynamic models suggest that contemporaneous income has the largest effect on achievement, with small effects from past income.

While modest, our instrumental variables estimates are larger than cross-section ordinary least squares (OLS) or standard fixed effects (FE) estimates. Several explanations may account for this difference. One is that income is noisily measured, so that OLS and FE estimates suffer from attenuation bias. It is also possible that income matters more for the most disadvantaged and that our instrument largely reflects the effect of income for these families. Perhaps the most interesting

\footnotetext{
${ }^{2}$ All dollar amounts are reported in year 2000 dollars, using the Consumer Price Index for all Urban Consumers (CPI-U) to adjust for inflation. The Tax Reform Act of 1986 began to adjust maximum credit amounts and phasein/phase-out regions for cost-of-living changes in years that did not specifically legislate changes in the EITC schedule. However, the federal tax adjustment is based on the CPI from the previous year (rather than the current year as used in our calculations). This explains why the reported maximum credit in our figures is about $\$ 30$ less in 1989 than it was in 1987.
} 
explanation is that expectations about future income play an important role in determining child outcomes. In this case, permanent changes in family income should have larger effects on children than do temporary changes. To the extent that changes in the EITC are expected to last longer than most idiosyncratic shocks to family income, our instrumental variables estimates should be greater than traditional OLS and fixed effect estimates (see Dahl and Lochner (2005)).

This paper proceeds as follows. In the next section, we give a brief literature review. Section 3 discusses our strategy for estimating the effect of family income on child outcomes. We then discuss the data and document the large changes in the EITC in Section 4. Section 5 presents estimates of the effect of income on math and reading test scores, including results from a variety of alternative specifications and robustness checks. Section 6 concludes.

\section{Previous Research}

A growing empirical literature questions how poverty affects a child's well-being and whether income support programs can improve a child's life chances. However, evidence on the extent to which family income affects child development is mixed. Previous studies differ in data, methods, and findings, as discussed in the collection of studies in Duncan and Brooks-Gunn (1997) or the surveys in Haveman and Wolfe (1995) and Mayer (1997).

Researchers have provided several explanations for why family income might affect child development. First, poverty is associated with increased levels of parental stress, depression, and poor health — conditions which might adversely affect parents' ability to nurture their children (see, e.g., McLoyd 1990). For example, in 1998, 27\% of kindergartners living in poverty had a parent at risk for depression, compared to $14 \%$ for other kindergartners (Child Trends and Center for Child Health Research, 2004). Low income parents also report a higher level of frustration and aggravation with their children, and these children are more likely to have poor verbal development and exhibit higher levels of distractability and hostility in the classroom (Parker et. al, 1999). Two recent working papers examine income transfer programs in Canada and the U.S. and find evidence that income transfers improve a family's emotional well-being. Milligan and Stabile (2009) find significant positive effects on self-reported child and maternal mental health, and Evans and Garthwaite (2010) find lower levels of self-reported maternal stress and a drop in the probability of risky levels of biomarkers associated with stress. Extra family income might also matter if parents use the money for child-centered goods like books, for quality daycare or preschool programs, for 
better dependent health care, or to move to a better neighborhood. ${ }^{3}$

Until very recently, empirical studies linking poverty and income to child outcomes have done little to eliminate biases caused by the omission of unobserved family and child characteristics. Most studies employ regressions of an outcome variable (such as scholastic achievement) on some measure of family income and a set of observable family, child, and neighborhood characteristics. While these studies reveal the correlations between income and child outcomes, they do not necessarily estimate a causal relationship as Mayer (1997), Duncan and Brooks-Gunn (1997), and others have pointed out. Children living in poor families may have a worse home environment or other characteristics that the researcher does not observe. These omitted variables may be part of the reason for substandard achievement and may continue to affect children's development even if family income were to rise.

Blau (1999), Duncan, et. al (1998), and Levy and Duncan (1999) use fixed effects estimation strategies to eliminate biases caused by permanent family or child characteristics. All three studies use differences in family income levels across siblings to remove fixed family factors when estimating the impacts of income on child outcomes. Using PSID data, both Duncan, et. al (1998) and Levy and Duncan (1999) find that family income at early ages is more important for determining educational attainment whether they control for fixed family effects or not. Using data from the Children of the NLSY, Blau (1999) reaches somewhat different conclusions. He estimates larger effects of "permanent income" when he controls for "grandparent fixed effects" (i.e. comparing outcomes for the children of sisters) than when he does not. However, he finds smaller and insignificant effects of current family income on achievement and behavioral outcomes when he uses fixed effect strategies (regardless of whether he uses comparisons of cousins, siblings, or repeated observations for the same individual) rather than OLS. While these studies represent a significant step forward, they do not control for endogenous transitory shocks (e.g. parental job loss or promotion, family illness, residential moves) and likely suffer from severe attenuation bias, since growth in income is typically noisily measured.

A few recent studies attempt to address these problems in a variety of ways. Two quasiexperimental studies estimate the impacts of government income transfers on children. Duncan, Morris and Rodrigues (2007) combine data from ten welfare and anti-poverty experiments in an attempt to identify the effect of family income separately from employment and welfare effects

\footnotetext{
${ }^{3}$ Children in poor families spend less time reading with their parents, are less likely to receive adequate health care and nutrition, and attend underfunded public schools, all of which are negatively associated with academic performance (Child Trends and Center for Child Health Research, 2004).
} 
induced by the programs. Milligan and Stabile (2009) estimate the impacts of changes in child tax benefits in Canada on child outcomes using variation in benefit changes by province and the number of children in the household. These studies find modest to large effects of family income on child educational and achievement outcomes that are largely consistent with our estimates. A second set of studies (Løken 2010, Løken, Mogstad and Wiswall 2010) estimates the impact of family income on the educational attainment and IQ of Norwegian children using regional variation in the economic boom following the discovery of oil as an instrument for income. Generalizing the specification of Løken (2010), Løken, Mogstad and Wiswall (2010) estimate that income has sizeable impacts on education and IQ among children from low-income families; however, those effects decline sharply among higher income families. ${ }^{4}$

The conclusions reached by recent studies suggest that unobserved heterogeneity and endogenous income shocks are important concerns. Furthermore, they suggest that income effects may be greatest among economically disadvantaged families. In the following section, we outline an instrumental variables strategy which eliminates omitted variable biases due to both permanent and temporary shocks correlated with family income and alleviates bias due to measurement error in income. Given our source of exogenous income variation (changes in the EITC), our strategy identifies the effects of family income on achievement for children from lower-income families.

Using our instrumental variables approach, we explore a few simple dynamic specifications of child achievement that allow for lasting effects of family income on children. Few previous studies explore dynamic relationships between family income and child achievement. Those that do tend to focus on the relative importance of family income received at different child ages and are subject to the same concerns about unobserved heterogeneity and endogenous family income shocks as described above. Most of these studies find that income received when a child is young has stronger lasting impacts than does income received during later childhood or adolescence (see Duncan and Brooks-Gunn 1997 and Duncan et al. 1998). ${ }^{5}$

\footnotetext{
${ }^{4}$ Other evidence from recent studies on the effects of parental education and job displacement indirectly suggests that family income may have important effects on children (Black, Devereux and Salvanes 2005, Oreopoulos, Page and Stevens 2006, 2008).

${ }^{5}$ Related studies estimate dynamic models of child development as a function of family and school inputs. For example, Todd and Wolpin (2007) estimate a dynamic model of both family and school inputs into child development. Their estimates imply strong lasting effects of family inputs (e.g. number of books in the home) but relatively weak effects of measured school inputs (e.g. teacher salary).
} 


\section{Methodology}

\subsection{Modeling Child Achievement}

Child achievement potentially depends on a child's ability, as well as other past and present child inputs (e.g. parental time, books, neighborhoods, schools, and home environments). Since family income affects decisions about investment in children, as well as parental stress and whether the general home environment is conducive to development, current and lagged family income have the potential to affect child outcomes at any particular age. In this section, we model how changes in family income (through such policies as the EITC) affect child achievement.

Let $x_{i}$ reflect observable permanent characteristics and $\mu_{i}$ reflect unobserved permanent 'ability' for child $i$ (i.e., a child fixed effect). These measures can also incorporate unobserved long-run differences across families. Let $w_{i a}$ reflect time-varying characteristics and $I_{i a}$ total family income (net of any taxes and transfers, including EITC payments) for child $i$ at age $a$. Finally, let $\varepsilon_{i a}$ denote any time-varying unobserved shocks to the child or family. Using this notation, a general model for child outcome $y_{i a}$ as a function of the child's family characteristics and income history is $y_{i a}=f_{a}\left(x_{i}, w_{i 0}, \ldots, w_{i a}, I_{i 0}, \ldots, I_{i a}, \mu_{i}, \varepsilon_{i a}\right)$. For empirical purposes, it is useful to simplify the child outcome equation as follows:

$$
y_{i a}=x_{i}^{\prime} \alpha_{a}+w_{i a}^{\prime} \beta+I_{i a} \delta_{0}+I_{i, a-1} \delta_{1}+\ldots+I_{i, a-L} \delta_{L}+\mu_{i}+\varepsilon_{i a},
$$

assuming that the effects of income on child achievement last for $L$ years. ${ }^{6}$

To focus on the role of income, equation (1) abstracts from the effects of past time-varying characteristics; however, these can easily be incorporated in the same way as past income. Equation (1) also abstracts from the possibility that income has different effects at different ages (i.e. effects depend only on the time elapsed between when income is earned and when child achievement is measured) or at different points in the income distribution (i.e. linearity in income is assumed). We explore these issues empirically below.

The specification in equation (1) allows for different effects of permanent characteristics at all ages (i.e. $\alpha_{a}$ ). In our empirical analysis, we allow $x_{i}$ characteristics (e.g. race, gender, and age of the child) to affect both the level and growth of child achievement. Taking first-differences of equation (1) to eliminate the unobserved fixed effect $\mu_{i}$ yields:

$$
\Delta y_{i a}=x_{i}^{\prime} \alpha+\Delta w_{i a}^{\prime} \beta+\Delta I_{i a} \delta_{0}+\Delta I_{i, a-1} \delta_{1}+\ldots+\Delta I_{i, a-L} \delta_{L}+\Delta \varepsilon_{i a},
$$

\footnotetext{
${ }^{6}$ One commonly used achievement model assumes that current achievement depends on current income and lagged achievement (e.g. $y_{i a}=x_{i}^{\prime} \alpha_{a}+w_{i a} \beta+I_{i a} \delta+y_{i, a-1} \rho+\mu_{i}+\varepsilon_{i a}$ ). Recursively substituting in for lagged values of achievement on the right hand side yields a specification very similar to equation (1) in which all lagged income measures and other time varying characteristics would also be included.
} 
where $\alpha \equiv \alpha_{a}-\alpha_{a-1}$ is the effect of $x_{i}$ on achievement growth (assumed to be age invariant).

A common achievement specification in the child development literature assumes that there are only contemporaneous effects of family income on children, ignoring any long-run effects. That is, $L=0$ in equations (1) and (2), which yields the following estimating equation in first-differences:

$$
\Delta y_{i a}=x_{i}^{\prime} \alpha+\Delta w_{i a}^{\prime} \beta+\Delta I_{i a} \delta_{0}+\Delta \varepsilon_{i a}
$$

This 'contemporaneous effects' model serves as our baseline and receives empirical support in our analysis. It is difficult empirically to estimate more general models which allow prior income in every year since birth to affect child outcomes. However, we also estimate specifications which allow one and two year lags.

\subsection{Using Changes in the EITC to Estimate the Effects of Income}

The primary concern with least squares estimation of the models above is the possibility that changes in unobserved factors affecting child development (i.e. $\Delta \varepsilon_{i a}$ ) are correlated with changes in family income. More generally, $\Delta \varepsilon_{i a}$ may be correlated with the entire history of income levels given the strong intertemporal correlation of income and its tendency for regression to the mean. To address this problem, we employ an instrumental variables (IV) estimation strategy that takes advantage of major changes in the EITC to estimate the effects of income on children. To simplify the discussion, we focus on the 'contemporaneous effects' model of equation (3); however, we take a similar approach in estimating the more general model implied by equation (2), which allows for lasting effects of income on children. (See the Appendix.)

We use total net family income (inclusive of EITC payments and net of other federal and state taxes and transfers) as our measure of total family income, $I_{i a}$. EITC income, $\chi_{a}^{s_{i a}}\left(P_{i a}\right)$, is a function of pre-tax income, $P_{i a}$, for the year when child $i$ is age $a$. We also take into account other taxes, $\tau_{a}^{s_{i a}}\left(P_{i a}\right)$. While the EITC and tax schedules do not generally vary with the child's age in any given year, they do sometimes change over time as the child ages. We exploit this time variation, referencing different years by age of the child, $a$. The superscript $s_{i a}$ on the EITC and tax functions denotes which schedule a child's family is on; the EITC schedules only differ based the number of children in the household, while the more general tax function depends on a broader set of family characteristics. ${ }^{7}$ Therefore, total net family income is given by

$$
I_{i a}=P_{i a}+\chi_{a}^{s_{i a}}\left(P_{i a}\right)-\tau_{a}^{s_{i a}}\left(P_{i a}\right)
$$

\footnotetext{
${ }^{7}$ Our empirical analysis takes many additional income and tax distinctions into account; we ignore them here for expositional purposes. See the Appendix.
} 
Central to our analysis is the variation in EITC schedules over time and the way in which EITC expansions have differentially augmented the incomes of different families.

Our IV estimation strategy builds on that of Gruber and Saez (2002) by assuming that changes in the EITC structure are independent of idiosyncratic family circumstances. ${ }^{8}$ As an instrument for $\Delta I_{i a}$ in estimating equation (3), we use

$$
\Delta \chi_{a}^{I V}\left(P_{i, a-1}\right) \equiv \chi_{a}^{s_{i, a-1}}\left(\hat{E}\left[P_{i, a} \mid P_{i, a-1}\right]\right)-\chi_{a-1}^{s_{i, a-1}}\left(P_{i, a-1}\right)
$$

where $\hat{E}\left[P_{i, a} \mid P_{i, a-1}\right]$ is an estimate of pre-tax income given lagged pre-tax income. In practice, we regress pre-tax income on an indicator for positive lagged pre-tax income and a fifth-order polynomial in lagged pre-tax income when calculating $\hat{E}\left[P_{i, a} \mid P_{i, a-1}\right]$. This effectively yields predicted changes in EITC income as a function of lagged pre-tax income, taking into account the fact that income evolves over time in a predictable way and that the EITC schedule changes in some years. ${ }^{9}$ By holding fixed the type of EITC schedule (1 vs. $2+$ children) $s_{i, a-1}$ in generating our instrument, we only exploit variation in predicted EITC income due to government changes in EITC schedules over time and not due to changes in family structure.

Of course, simply estimating equation (3) using $\Delta \chi_{a}^{I V}$ as an instrument is likely to yield biased estimates for $\delta_{0}$, since changes in families' simulated EITC payments are a function of age $a-1$ pretax family income $\left(P_{i, a-1}\right)$, which is likely to be correlated with the subsequent change in income due to such factors as measurement error, regression to the mean, and serially correlated income shocks. Therefore, based on the insight of Gruber and Saez (2002), we augment the outcome equation with a flexible function of $P_{i, a-1}$ when instrumenting. Letting $\Phi\left(P_{i, a-1}\right)$ reflect a flexible function of lagged pre-tax income, we estimate

$$
\Delta y_{i a}=x_{i}^{\prime} \alpha+\Delta w_{i a}^{\prime} \beta+\Delta I_{i a} \delta_{0}+\Phi\left(P_{i, a-1}\right)+\eta_{i a}
$$

using $\Delta \chi_{a}^{I V}$ as an instrument for $\Delta I_{i a}$. Empirically, we employ the same functional form for $\Phi\left(P_{i, a-1}\right)$ as we use in estimating $\hat{E}\left[P_{i, a} \mid P_{i, a-1}\right]$ : we include an indicator for positive lagged pre-tax income and a fifth order polynomial in lagged pre-tax income. This ensures that the variation

\footnotetext{
${ }^{8}$ This strategy is loosely related to Feldstein (1995) and Currie and Gruber (1996), who use the effects of policy changes on economy-wide aggregates rather than the distributional consequences of policy changes to identify their parameters of interest. See Moffitt and Wilhelm (2000) for a general discussion of the simulated IV methodology and its application.

${ }^{9}$ The ideal (i.e. most efficient) instrument would be $E\left[\chi_{a}^{s_{i, a-1}}\left(P_{i, a}\right) \mid P_{i, a-1}\right]-\chi_{a-1}^{s_{i, a-1}}\left(P_{i, a-1}\right)$. In practice, age $a$ EITC income is difficult to predict based on lagged income due to non-linearity and discontinuities in the EITC schedule. An intuitive approach would simply use lagged pre-tax income $P_{i, a-1}$ in place of $\hat{E}\left[P_{i, a} \mid P_{i, a-1}\right]$ in creating our instrument. This strategy (when incorporating the control function as discussed below) yields consistent but much less precise estimates compared to the approach taken here.
} 
in our instrument used to identify $\delta_{0}$ comes from changes in the EITC schedule and not from the level of lagged pre-tax income. Intuitively, this strategy estimates the extent to which the differential income boosts associated with the EITC expansions (as determined by past income levels) are met with increases in child achievement. If income has a positive effect on achievement, we should observe greater increases in test scores among children from low-income families relative to high-income families when the EITC expands. ${ }^{10}$

One can think of the polynomial $\Phi\left(P_{i, a-1}\right)$ in equation (4) as a control function. It is, therefore, important that $\Phi(\cdot)$ be flexible enough to capture the true expected relationship between child development shocks and lagged pre-tax income - we use a very flexible polynomial in lagged pretax income. In the most general case, the control function should equal $E\left[\Delta \varepsilon_{i a} \mid P_{i, a-1}, x_{i}, \Delta w_{i a}\right]$. As such, if the evolution of income over time differs systematically with $x_{i}$ or $\Delta w_{i a}$ or if the relationship between $\Delta \varepsilon_{i a}$ and pre-tax income depends on $x_{i}$ or $\Delta w_{i a}$, then the control function should be generalized to account for these relationships. Recognizing this possibility, we consider alternative specifications using a more general control function that interacts $\Phi\left(P_{i, a-1}\right)$ with all $x_{i}$ and $\Delta w_{i a}$ regressors. ${ }^{11}$

Our approach relies on one fundamental assumption: the relationship between child development shocks and lagged pre-tax income must be stable over time. In using a time invariant control function $\Phi(\cdot)$, our baseline analysis implicitly assumes that the relationship between $\Delta \varepsilon_{i a}$ and pretax income does not vary with time over our sample period. To relax this assumption, we explore additional specifications that allow the control function to evolve smoothly over time or to vary state by state in response to changes in state welfare or school accountability policies. However, it is not possible to allow the control function to vary freely over time, since this would eliminate any independent variation in our instrument $\Delta \chi_{a}^{I V}\left(P_{i, a-1}\right)$.

With a fully flexible (time invariant) control function, all identification comes from differential changes in the EITC schedule over time. Our strategy would break down if the EITC schedule did not change during our sample period, since there would be no independent variation in our instrument given the control function $\Phi\left(P_{i, a-1}\right)$. In fact, our approach requires at least three periods of data, since we need at least two different changes in the EITC schedule over time given a flexible

\footnotetext{
${ }^{10}$ Figure 1b makes clear that the largest changes in our instrument occur for low to moderate income families. If $\hat{E}\left[P_{i, a} \mid P_{i, a-1}\right]=P_{i, a-1}$, then the value of the instrument over time (as a function of pre-tax income) would be as illustrated in Figure 1b. However, for very low earnings families, $\hat{E}\left[P_{i, a} \mid P_{i, a-1}\right]>P_{i, a-1}$ since their earned income is predicted to rise. The time invariant control function accounts for the fact that the value of the instrument varies by income even when the EITC schedule does not change. As discussed below, our approach requires that the EITC schedule itself must change over time to identify the effect of income on child achievement.

${ }^{11}$ The Appendix provides a more detailed discussion of these issues. See Heckman and Robb (1985) for a general treatment of control functions. Linear spline functions yield similar results to those presented in the paper.
} 
control function. To better understand identification, suppose that income did not change at all over time. In this case, any changes in after-tax income would be driven solely by changes in the EITC schedule. The validity of our research design, therefore, hinges on controlling flexibly for pre-tax income with the control function. The fact that we use lagged pre-tax income is second order.

Two minor practical issues arise in our analysis. First, the vast majority of EITC recipients receive their credit after filing their taxes the following year. Therefore, we link test scores (typically measured sometime between March and December in our data) with income earned in the previous calendar year (reported during the same survey as test scores are recorded), referring to them as 'contemporaneous'. Second, we only observe child achievement scores every other year as we discuss further below. Thus, we use two-year differences rather than one-year differences in our analysis. The Appendix briefly describes how this affects the estimating equations above.

\section{Data}

We use data from the Children of the NLSY and the main NLSY sample of mothers. These data are ideal for studying the effects of family income on children for several reasons. First, we can link children to their mothers, and second, we can follow families over time. Third, the NLSY contains repeated measures of various child outcomes and comprehensive measures of family income. Finally, the NLSY oversamples minority families, which provides a larger sample of families eligible for the EITC. We exclude children from the oversamples of poor white families and military families.

The NLSY collects a rich set of variables for both children and mothers repeatedly over time, allowing us to estimate models with child fixed effects. For children, biennial measures of family background and cognitive achievement are available from 1986 to 2000. Detailed longitudinal demographic, educational, and labor market information for the mothers is available annually from 1979 through 1994 and biennially thereafter. Equally important, family income measures (for the previous calendar year) are available in all survey years for the mothers up to 1994 and biennially thereafter. The survey reports many components of family income, which we aggregate into three categories of pre-tax/EITC income: earned income, unearned income, and non-taxable income. See the Online Appendix for a description of these income categories and how we impute missing observations.

While the NLSY contains a broad array of income questions, it does not ask an individual how much they received in EITC payments or paid in taxes. Both the IRS (2002) and Scholz (1994) 
estimate that roughly 80 to 87 percent of eligible households receive the credit. We implicitly assume full take-up and impute each family's state and federal EITC payment and tax burden using the TAXSIM program (version 9) maintained by Daniel Feenberg and the NBER (see Feenberg and Coutts, 1993 and http://www.nber.org/taxsim).

In our analysis, we focus on measures of scholastic achievement in math and reading based on standardized scores on Peabody Individual Achievement Tests (PIAT). The assessments measure ability in mathematics, oral reading and word recognition ability (reading recognition), and the ability to derive meaning from printed words (reading comprehension). From 1986 to 2000, the tests were administered biennially to children ages five and older; although, $92 \%$ of our estimation sample is between the ages of 8 and 14 . Children took each individual test at most five times due to the age restrictions. See the Online Appendix for details.

To make the PIAT test scores more easily interpretable, we create normalized test scores with a mean of zero and a standard deviation of one based on the random sample of test takers (i.e. excluding the poor, military, and minority oversamples). We also create a combined math-reading score, which takes the average of our normalized math and reading scores. This is then re-normalized to have a mean of zero and standard deviation of one in the random sample. Our full sample that includes oversamples of blacks and hispanics has negative average normalized test scores, since children in the oversamples are more disadvantaged on average.

We restrict our main sample to children observed in at least two consecutive (even-numbered) survey years between 1988 and 2000 with valid PIAT scores, family background characteristics, and family income measures, since our primary analysis estimates models with child fixed effects. ${ }^{12}$ Because changes in family income are likely to mean something very different when there is a change of marital status relative to when there is not, we also limit our sample to children whose mothers did not change marital status during two-year intervals when test scores are measured. Our main sample includes 4,412 interviewed children born to 2,401 interviewed mothers, with children observed 2.2 times on average. Table 1 provides information on family income and EITC eligibility over time for this main sample. The table reveals that median after-tax family income rose in real terms from $\$ 23,463$ reported in 1988 to $\$ 38,390$ reported in 2000 . The time trend in family income, which outpaced inflation, is largely attributable to the aging of mothers in the sample. The

\footnotetext{
${ }^{12}$ We exclude the 1986 survey year and survey years 2002 onward to focus our analysis on changes in the EITC, rather than the large changes in the tax code associated with the Tax Reform Act of 1986 and the two 'Bush' tax cuts in 2001 and 2003. To focus on EITC changes, we also exclude observations with family income levels above $\$ 100,000$; although, including these observations has negligible effects. To minimize the influence of outliers and obvious measurement error, we also trim observations with very large changes in income or large and unusual changes in reported welfare income. See the Online Appendix for details.
} 
relevance of changes in the EITC schedule over time is also evident in Table 1. Roughly one-third of children live in families which qualify for the EITC, a high rate that is partly due to the NLSY oversampling of minorities. The largest EITC expansion is reflected in the sizeable increase in EITC eligibility and payment amounts for 2+ child families between 1994 and 1996.

Table A1 in the Appendix describes sample characteristics based on EITC eligibility. Panel A lists variables for the child that are included as controls in our baseline 'difference' specifications: child gender, age, number of siblings, and race. Panel B includes additional variables used as controls in our OLS 'levels' regressions and a robustness specification. These include mother's characteristics like age, completed education, AFQT score, and whether she lived with both natural parents at age 14. It also includes the mother's marital status in the previous year (corresponding to the year income is measured), household composition variables, spouse's age, and education measures of the mother's parents and spouse.

Column (i) provides summary statistics for our full sample. The average age of the children in our sample is 11 and most children have at least one sibling. Over half the sample is black or hispanic due to the oversampling of minorities. The average age of mothers is 33 years old, although the youngest mother with a child in our sample is 25. Columns (ii) and (iii) in Table A1 break down the summary statistics based on EITC eligibility, while column (iv) reports the difference between eligible and ineligible families. Children from EITC eligible families (relative to those that are ineligible) are more likely to be minorities and have mothers with less education and lower AFQT scores. Their parents are also less likely to be married. These differences suggest that some children will be more directly affected by changes in the generosity of the EITC (e.g. black children with unmarried, low educated mothers versus white children with married, highly educated mothers).

\section{The Effect of Income on Cognitive Achievement}

In this section, we discuss the estimated impact of family income on children's math and reading achievement. We first report standard OLS and differenced estimates of outcome equations (1) and (2) under different assumptions about the dynamic effects of income. We also briefly discuss estimates for a few additional specifications previously employed in the literature. We then turn to our IV estimation strategy, which accounts for measurement error, permanent unobserved heterogeneity, and temporary unobserved shocks. We explore whether income changes have lasting effects on child achievement, whether the effects vary across different demographic groups, and 
whether income differentially affects younger versus older children. To establish the robustness of our findings, we examine a number of different specifications, including regressions which account for time-varying state policies, more general control functions, and maternal labor market participation.

\subsection{OLS and Differenced Estimates}

We begin by presenting OLS and differenced estimates of the effects of family income on our combined math-reading measure of cognitive achievement. As a reminder, the differenced estimates are based on two-year differences, since children are only administered the PIAT tests every other year. Compared to most studies, we estimate more general models of child achievement, exploring whether income has lasting effects on children.

Table 2 reports estimates of equations (1) and (2) under different assumptions about the persistence of income effects. In the levels models we regress child achievement on total income and include all the variables reported in Table A1 as controls. The specification we estimate in differences is slightly more general, since we allow achievement growth to vary by the child characteristics listed in panel A of Table A1. Column (i) assumes the 'contemporaneous effects' model used by many previous studies. Estimated in levels, we find that a $\$ 1,000$ increase in family income raises math-reading test scores by 0.005 standard deviations. Estimated in differences, the effect is less than one-fourth as large and no longer significant. These estimates are similar to corresponding estimates in Blau (1999).

There are two reasons to expect a discrepancy between difference (or fixed effects) and crosssectional OLS estimates. First, measurement error is greater for income measured in differences than in levels, so attenuation bias will be greater for difference estimators. Second, a correlation between unobserved fixed effects $\left(\mu_{i}\right)$ and family income will bias cross-sectional OLS estimates. The first bias is greater for difference estimates while the second only affects cross-sectional OLS, so there is no a priori reason to prefer one type of estimator over the other. More importantly, both approaches suffer from additional bias if unobserved transitory shocks to families and children are correlated with family income.

Columns (ii)-(iv) estimate more general models that allow for the possibility that income effects persist for up to two years into the future. Column (iii) reveals the difficulty in identifying the persistence of income effects beyond one year due to the high degree of collinearity in earnings over time. To improve precision but still allow for a difference between contemporaneous and past income, column (iv) imposes $\delta_{1}=\delta_{2}$ but allows for a separate effect of contemporaneous income, 
$\delta_{0}$. The levels specifications in Panel A suggest that income effects are quite small and may last for a few years, while difference estimates in Panel B suggest even smaller effects for current and lagged income. For both panels, we also report the implied medium-term effects of increasing income by $\$ 1,000$ each year for up to three years. This is simply the sum of the estimated effects of current and lagged income. These are quite modest and similar across columns (ii)-(iv), and suggest that the coefficient in column (i) understates the medium-run effect of a sustained increase in income.

An alternative specification often seen in the literature regresses child achievement on a longrun average of family income (generally averaging over all available income measures from the past, present, and future). This specification is economically motivated by the standard lifecycle or permanent income model, which assumes family investments in children depend on lifetime or 'permanent' income rather than income in any particular period. Implicit is the assumption that families can borrow and save in order to smooth their consumption and child investments over time. A separate statistical argument can also be made for regressing child achievement on average income rather than income received in any particular period. Because income is measured with error, standard OLS level and differenced estimators will tend to be biased towards zero, and averaging may alleviate this problem. In practice, previous studies tend to estimate larger effects of average income than of current income (e.g. Blau 1999). We find the same pattern: the relationship between long-run average income and test scores is $70 \%$ larger compared to the relationship between current income and achievement. One concern with using average long-run family income is the difficulty in accounting for unobserved long-run heterogeneity using fixed effects strategies. Since average family income is likely to be more strongly correlated with unobserved family characteristics than is income for any particular period, estimates using long-run averages of family income may be subject to greater omitted variable bias.

\subsection{Estimates}

We now turn to our IV approach to estimate the effects of family income on child achievement. We begin with our simple 'contemporaneous effects' model in differences (equation 3) using simulated changes in the EITC (based on lagged income) as instruments for changes in actual after-tax/EITC total family income. As a practical matter, identification comes primarily from the substantial expansion of the EITC schedule between 1993 and 1995; however, other smaller changes in the EITC schedule also aid in identification. The approach reveals whether achievement scores systematically increased more for families who were predicted to receive a greater boost in EITC payments during years when the schedule expanded. 
Our approach requires inclusion of a flexible function of lagged pre-tax income as detailed in equation (4). We explored different ordered polynomials and found the estimates to be very similar for orders four and above if we also include an indicator for positive lagged pre-tax income. To be conservative, we use a fifth order polynomial in lagged pre-tax income and an indicator for positive lagged pre-tax income as our baseline 'control function'. Our baseline specification allows for differential growth in achievement based on a child's gender, age, number of siblings, and race. Below, we show that the results are similar for specifications with additional controls (i.e. other factors affecting growth in test scores) and with more general control functions that interact included regressors with the polynomial in income.

Table 3 reports baseline IV estimates for our combined math-reading achievement measure, as well as each of the individual PIAT subject test measures. The results in column (i) imply that a $\$ 1,000$ increase in family income raises math-reading achievement by $6 \%$ of a standard deviation, a modest effect, but much larger than the comparable OLS estimates in column (i) of Table $2 .{ }^{13}$ To place this estimate in perspective, in the OLS levels specification, having a mother who is a high school graduate (versus a high school dropout) is associated with an increase of $17 \%$ of a standard deviation in achievement. Looking at columns (ii) - (iv) in Table 3, the estimated effects of income are noticeably lower for reading recognition, while the estimated effects of income on reading comprehension and math are similar to the effects for our combined math-reading measure.

This table also reports the coefficient on our instrument in the first stage regression of changes in total family income on changes in predicted EITC receipt. It is slightly larger than one, but not significantly so. In general, this coefficient may deviate from one due to labor supply responses to the EITC expansions or due to measurement error in income. As we discuss later in the paper, we find some evidence of a modest effect operating through labor supply.

The key assumption in our analysis is that the relationship between child achievement growth and lagged pre-tax income should be relatively stable over time if the EITC schedule is not changing. Identification relies on linking changes in the income - achievement relationship with changes in the EITC schedule over time. Of particular concern are systematic economic or policy changes that would improve the test scores of children from lower-income families at the same time the EITC expanded (most notably from 1993 to 1995). In this case, our IV estimators would mistakenly

\footnotetext{
${ }^{13}$ Since we use two-year differences in income and child outcomes, these estimates reflect the effects of increasing annual income by $\$ 1,000$ for up to two years. As we show below with dynamic achievement specifications, these estimates largely identify the impact of increasing income in the current year by $\$ 1,000$, since earlier increases in income appear to have small lasting effects. The estimates could also be inflated by about $15-20 \%$ to account for the fact that EITC take-up rates are estimated to range from 80 to $87 \%$ (IRS 2002, Scholz 1994).
} 
attribute the achievement gains of disadvantaged children to the increased income their families received from expansions of the EITC. We explore specifications in Table 4 that take into account national time trends and changes in state-level school accountability and welfare policies. To conserve space, we only report estimates for our combined math-reading achievement measure.

The first specification in Table 4 includes year dummies in our baseline specification. This allows average test scores to vary freely from year to year, and forces identification of our IV estimate to come entirely from differences in predicted EITC changes across individuals (by lagged pre-tax income) between any two years. ${ }^{14}$ This yields a similar point estimate (significant at the 0.10 level) to that of Table 3, but the standard error increases by two-thirds. Specifications B and C in the table allow for a linear time trend in test score growth; specification $\mathrm{C}$ also interacts the time trend with the control function $\Phi\left(P_{i, a-1}\right)$ (i.e. the polynomial in lagged pre-tax income and an indicator for positive lagged pre-tax income). These specifications yield larger (and less precise) estimates when compared with our baseline estimate in Table 3. By interacting the time trend with the control function, we address the concern that the relationship between child outcomes and pre-tax income is changing over time.

The next two specifications in Table 4 address changes in state policies that might directly affect the relationship between child outcomes and family income or characteristics: school accountability policies and welfare regulations. A few states began to introduce student testing/accountability measures and welfare reforms in the early 1990s, which some studies have linked to improvements in state test scores (e.g. Hanushek and Raymond (2005) and Miller and Zhang (2008)). ${ }^{15}$ To account for these reforms, we add an annual indicator for whether the child's state has a 'consequential' accountability policy (i.e. required testing with consequences for school performance) to our baseline specification. The next specification examines whether accounting for welfare reforms taking place in the 1990s (associated with statewide AFDC waivers and TANF) affects our results. This specification includes an annual indicator equal to one if a state has any of the following: (a) time limits on welfare receipt, (b) sanctions for violating work requirements, or (c) school requirements for dependent children. (These specifications also include interactions between accountability or welfare reform and the control function.) As Table 4 shows, these additions have little affect on

\footnotetext{
${ }^{14}$ Without time dummies, our estimates are identified even if everyone experienced the same predicted EITC change between years as long as the EITC expanded more in some years than others. Our IV specifications that do not include time dummies are identified from changes in average EITC income and test scores over time as well as differential changes in EITC income and test scores across individuals between particular time periods.

${ }^{15}$ Most states did not introduce school accountability policies or welfare reforms prior to 1996 . A number of states received Aid to Families with Dependent Children (AFDC) waivers in the early 1990s; however, most states introduced welfare reforms with the introduction of the Temporary Assistance for Needy Families (TANF) program in 1996. See the Online Appendix for a detailed description of our school accountability and welfare policy measures.
} 
our estimates. Finally, the last specification of Table 4 simultaneously accounts for national time trends, state-level school accountability, and state-welfare reforms. The results are nearly identical to our baseline estimates (with larger standard errors). In summary, we find no evidence that time-varying policies or economic changes materially affect the estimated impacts of family income on child achievement.

In Table 5, we return to dynamic models of child achievement that allow for lasting effects of family income on children. We report estimates for the combined math-reading achievement measure analogous to those of Table 2. Due to the limited number of major changes in the EITC schedule, we only estimate the effects of income lasting up to two years into the future. These specifications instrument for lagged income changes, including the appropriate control function, using a similar approach to that used for the contemporaneous effects model (see the Appendix for details). Columns (i) and (ii) allow for the possibility that income affects test scores up to one or two years later. Both specifications suggest sizeable effects of contemporaneous income and effects of past income which are smaller. Given the sizeable standard errors when multiple years of income are included, column (iii) restricts both one- and two-year lagged income to have the same effect (i.e. $\delta_{1}=\delta_{2}$ ). This specification provides more precise estimates, but yields the same conclusion: contemporaneous income plays an important role in achievement, with smaller effects from past income. ${ }^{16}$ The table also reports the implied medium-term effects of a sustained increase in income for up to three years. These medium-term effects are up to $50 \%$ larger than the contemporaneous effect estimated in Table 3 .

We draw two main conclusions from Table 5. First, there are small, but statistically insignificant, effects of lagged income on math and reading achievement scores. The medium-term effects suggest that our baseline estimates in Table 3, if anything, understate the effects of lasting income changes on child achievement. Second, income appears to have important contemporaneous effects on child achievement. Moreover, incorporating lasting effects of income does not substantially alter the fact that income has a sizeable contemporaneous effect. So, while one would certainly like to more fully determine the dynamic effects of family income on achievement, the simple 'contemporaneous effects' model appears to provide reasonably good estimates of the short-run effects of income. We focus on this baseline model in the remaining two tables.

Table 6 displays estimates from separate regressions for various population subgroups. Estimates in the table reflect the impact of a $\$ 1,000$ increase in current income on combined math and

\footnotetext{
${ }^{16} \mathrm{~A}$ number of recent studies estimate similarly strong fade-out effects for the 'value added' of individual teachers on student test scores (e.g. Lockwood, et al. 2007, Jacob, Lefgren and Sims 2008, and Rothstein 2008).
} 
reading achievement for the reported subgroups. The extent to which different subgroups are more or less affected by changes in the EITC is reflected in the 'Percent in EITC Range' for each group. Higher socioeconomic status (SES) groups have a lower probability of being affected by the EITC and, therefore, a smaller instrumented change in income on average. This is reflected in the fact that the first stage estimates for high SES groups typically have standard errors that are twice as large as those for low SES groups.

Except for the final two columns, the table is organized such that estimates for more economically disadvantaged groups are reported at the top while estimates for more advantaged groups are at the bottom. Achievement for children with low educated mothers increases significantly with income, while achievement for children whose mothers attended at least some college is largely unresponsive to income changes. One should exercise caution in interpreting the latter, however, since the first stage is quite weak for children with more educated mothers. Changes in EITC schedules do not provide a very good source of income variation for these families. We also estimate strong and statistically significant effects of family income on the achievement of minority children; in contrast, our estimates for whites are substantially smaller and the first stage is imprecise. Point estimates also suggest that income raises test scores more among children in unmarried households relative to married households, and more for children whose mother's AFQT score is below the median compared to above the median; however, these estimates are fairly imprecise. Overall, these estimates suggest that the effects of family income are greater for more disadvantaged children; although, the difference is only statistically significant by maternal education.

A number of recent studies (e.g. Duncan and Brooks-Gunn 1997, Duncan, et al. 1998, Levy and Duncan 1999) suggest that income at early ages may have greater effects on development than income received at later ages. In the second to last column of Table 6, we estimate the effects of income separately for children age 11 or younger versus age 12 or older. These estimates suggest slightly larger effects of income on achievement for younger children, although the difference is not statistically significant. Unfortunately, we are unable to examine the effects of income at very early ages, which is when many researchers find the largest effects. This is because most children in our sample (92\% of the children) are ages 8 through 14 when they take the PIAT tests. ${ }^{17}$

In the final column of Table 6 , we estimate separate models for boys versus girls. The effect of income for boys is twice as large as that for girls, although the standard errors are large enough

\footnotetext{
${ }^{17}$ One of the PIAT components (reading recognition) initially had problems which invalidated test scores for many young children. Using the average of the math and reading comprehension tests only, which includes all children beginning at age five, we find a similar pattern by age: the estimated effect of income is $0.062($ s.e. $=0.032)$ for children age 11 or younger and 0.033 (s.e. $=0.022$ ) for children age 12 or older.
} 
that the difference is not statistically significant. This result is similar to that found by Milligan and Stabile (2009), who find that increased child benefit levels in Canada had stronger effects on the academic performance of boys compared to girls.

Table 7 presents several additional specifications for the 'contemporaneous effects' model (combined math-reading measure) to explore the robustness of our baseline results. Specification A includes additional control variables such as the mother's age and education, her family background, and her spouse's characteristics in the differenced child outcome equation, while specification B removes all control variables (except the control function) from our baseline specification. Neither change in control variables has much impact on the estimated effect of family income. We next explore a more general control function in specification $\mathrm{C}$, interacting all of the baseline control variables with lagged pre-tax income and the polynomial in lagged pre-tax income. These interactions address the concern that the relationship between child outcomes and lagged income differs based on the baseline controls. This more general control function does not appreciably change the estimate.

Our estimates exploit variation in both state and federal EITC schedules when constructing our instruments. Specification D shows that the inclusion of state fixed effects in our specifications has little impact on the coefficient of interest. This is true regardless of whether we use the state EITCs to construct our instruments. Because few states had EITC provisions during our sample period ( 5 states by 1996 and 10 states by 1999), the results are very similar when only using federal changes in EITC schedules to construct our instruments.

Specification E in Table 7 uses NLSY-created weights for the initial sample of mothers to weight observations. These estimates indicate a slightly smaller effect of family income on achievement; however, the standard error is $12 \%$ larger than that of our baseline estimates without weights. ${ }^{18}$

Table 6 suggests that the effects of income may be stronger for more disadvantaged children. Under this assumption, some researchers have preferred to measure income in logs rather than levels. For comparison and as a check on the robustness of our findings, specification F of Table 7

\footnotetext{
${ }^{18}$ Two arguments are often made for using sampling weights. First, they can produce more efficient estimates. However, this is not generally true in the case of IV estimation and does not appear to be true in our application based on a comparison of standard errors. A second argument sometimes made for using sampling weights is based on heterogeneous 'treatment effects' and the desire for estimating a population average effect. Since blacks and hispanics are over-represented in our sample, one might want to use sampling weights to obtain a population 'average' effect of family income on achievement. However, IV does not generally yield a population average effect, except in rare cases (see, e.g., Heckman and Vytlacil 1998, Imbens and Angrist 1994, Wooldridge 1997). In our context, estimates using the sampling weights should place a larger weight on the effect for whites vs. minorities. Thus, the slightly smaller estimate for specification D relative to our baseline estimate in Table 3 is consistent with the finding in Table 6 that income effects are larger for minorities than for whites.
} 
uses log total family income as the right-hand side variable rather than income measured in levels. ${ }^{19}$ This specification implies that a $10 \%$ increase in family income raises achievement by $6.4 \%$ of a standard deviation. For families with income of $\$ 12,000$, an extra $\$ 1,000$ would raise child mathreading scores by 0.053 of a standard deviation, similar to our baseline IV estimate that uses income measured in levels.

It is natural to question whether the large changes in the EITC generated important labor supply responses among mothers which may have affected children separately from the direct effects of income we aim to measure. In principle, an EITC expansion may affect children in three ways. First, holding earnings constant, it increases family income. Second, it may affect earnings through family labor supply responses. Both of these affect children through available family resources. Finally, labor supply responses may directly affect children through parental time spent with children. If labor supply responses to EITC schedule changes are small, the second and third effects will be negligible, and our baseline estimates identify only the first effect. More generally, we can identify the effect of total income changes (i.e. the sum of the first two effects) by controlling for labor supply.

Most empirical studies find very small negative effects of the EITC expansions on hours worked by women who were already working. The literature also finds a positive effect on labor market participation among single mothers, but small negative effects on married mothers with working husbands (see Hotz and Scholz 2003 and Eissa and Hoynes 2005). Specification G of Table 7 adds changes in maternal labor force participation and hours worked to our baseline specifications as additional controls. An increase in the number of hours a mother works has small negative estimated effects on children, whereas participation changes have statistically insignificant effects. Most importantly, accounting for changes in mother's labor market participation and hours of work does not affect our main conclusion about the importance of family income. ${ }^{20}$

Recall that total income increased by $\$ 1.27$ for a $\$ 1$ increase in predicted EITC payments in the first stage of the baseline specification. The fact that the coefficient is slightly larger than one (although not significantly so) is consistent with a modest bonus impact through increased labor

\footnotetext{
${ }^{19}$ In this specification, we use $\ln \left(\hat{E}\left[P_{i, a} \mid P_{i, a-1}\right]+\chi_{a}^{s_{i, a-1}}\left(\hat{E}\left[P_{i, a} \mid P_{i, a-1}\right]\right)\right)-\ln \left(P_{i, a-1}-\chi_{a-1}^{s_{i, a-1}}\left(P_{i, a-1}\right)\right)$ as an instrument for $\Delta \ln \left(I_{i a}\right)$.

${ }^{20}$ The endogeneity of which mothers work and how much they choose to work is an obvious concern. We attempted to treat participation as endogenous by using changing parameters of the EITC schedules (e.g. maximum credit amounts, phase-in and phase-out rates) over time as additional instrumental variables for maternal labor market participation (an approach similar in spirit to Blundell, et. al 1998, and Eissa and Hoynes 2006). This approach yields statistically significant estimates for family income that are very similar to our baseline estimates; however, it produces imprecise estimates for maternal labor force participation. Unfortunately, the first stage for maternal labor supply indicates the instruments are weak in our sample.
} 
supply. Indeed, once labor supply is controlled for in panel G, the first stage coefficient drops to 0.90 .

\subsection{Interpreting IV Estimates}

Our IV results indicate modest but encouraging effects of family income on children's scholastic achievement. Our baseline estimates imply that a $\$ 1,000$ increase in income raises combined math and reading test scores by $6 \%$ of a standard deviation. Although modest in an absolute sense, our estimates are large relative to much of the literature and relative to the OLS and differenced estimates reported in Table 2. Duncan, Morris, and Rodrigues (2007) also report IV estimates of the effect of family income on child achievement that are much larger than their OLS estimates. Their IV strategy exploits randomly assigned variation in family income supplements from ten different income support and welfare experiments to identify the causal effect of income. Looking at expansions in the Canadian child benefit program, Milligan and Stabile (2009) find even larger effects of extra income on children's test scores than we do. Like our approach, these two papers use exogenous variation in income and focus on relatively disadvantaged families.

We speculate that a variety of factors may be responsible for our larger IV estimates relative to traditional OLS and fixed effects or differenced estimates. A first possibility is that measurement error produces attenuation bias for standard methods. Fixed effects and differenced estimators are particularly affected by this problem, since changes in income are noisier than income measured in levels. However, measurement error alone is unlikely to explain most of the gap between our IV estimates and more traditional estimates. As reported in Section 5.1, the estimated effect of average income (which should have less measurement error) is $70 \%$ larger compared to the estimated effect of contemporaneous income in OLS specifications (0.0080 versus 0.0047$)$ but still much smaller than our IV estimates.

A second potential explanation is that income matters more for disadvantaged families and that our IV estimates capture the effects of income for disadvantaged families who are affected by the EITC expansions. Table 6 offers some support for this explanation. Furthermore, Løken, Mogstad and Wiswall (2010) argue that nonlinear effects explain why OLS and FE estimators find little evidence that family income matters, since these estimates place relatively little weight on poor families in most studies. To further explore this issue, we split the sample into low, middle, and high average total family income groups and use OLS to estimate separate effects of income for each group. ${ }^{21}$ The effect of a $\$ 1,000$ increase in average income is 0.026 (s.e. $=0.009$ ) for the bottom

\footnotetext{
${ }^{21}$ Given the NLSY oversampling of minorities, our data contains a large number of low and moderate income
} 
quartile, 0.010 (0.004) for the middle two quartiles combined, and 0.010 (0.004) for the highest quartile. The effect for the lowest income group is much larger than the effects for higher income groups and closer to our IV estimates.

A third explanation recognizes that each EITC expansion effectively raised the annual incomes of eligible families for many years in the future. For example, we estimate that for the median EITC recipient, the 1993-95 EITC expansion raised total credit amounts over the years 1995-99 by nearly four times the amount it raised credit amounts in 1995 alone. ${ }^{22}$ If families are forward-looking and base their investment decisions on current and expected future income, we would expect them to respond more to a lasting change in income than to a one-year change. A lasting increase in income is also likely to alleviate family stress and improve family dynamics more than a comparable temporary increase. In this case, our IV estimator identifies the effect of increasing annual income by $\$ 1,000$ for many years into the future and not just a single year. On the other hand, OLS and difference estimators identify the effect of a much more short-lived increase in income, since most of the underlying variation in income over time is transitory (or measurement error). Thus, it is not surprising that our IV estimates exceed our OLS and difference estimators. See Dahl and Lochner (2005) for a more formal discussion of these issues.

A final possible explanation for larger IV estimates may have to do with the nature of EITC income relative to other income sources. Three features of the EITC are somewhat special. First, the EITC is typically paid out in lump sum fashion after families file their taxes (many EITC recipients even receive an automatic refund at filing), and families may spend these lump-sum transfers differently than they spend more traditional income flows (Barrow and McGranahan (2000) and Goodman-Bacon and McGranahan (2008)). Second, since EITC payments explicitly depend on having children in the household, families may feel some obligation to spend it on their children. Third, EITC payments come in the mail with tax returns or are direct deposited into family accounts. As such, mothers may be more likely to gain control of EITC payments than fathers (compared to other sources of income). A number of studies empirically find that household expenditures on children increase with the share of family income going to mothers (e.g. Lundberg, Pollak, and Wales 1997, Attanasio and Lechene 2002, and Ward-Batts 2008).

families. The lowest quartile corresponds to families earning less than $\$ 18,031$ on average, the middle two quartiles between $\$ 18,031$ and $\$ 41,790$, and the fourth quartile greater than $\$ 41,790$.

${ }^{22}$ To empirically investigate the persistence of EITC gains for families, we divide the cumulative three-year credit increase (for 1995, 1997, and 1999) by the one-year credit increase for 1995 resulting from the large EITC expansion that took place between 1993 and 1995. Specifically, we calculate $\frac{\left[\chi_{95}\left(P_{95}\right)+\chi_{95}\left(P_{97}\right)+\chi_{95}\left(P_{99}\right)\right]-\left[\chi_{93}\left(P_{95}\right)+\chi_{93}\left(P_{97}\right)+\chi_{93}\left(P_{99}\right)\right]}{\chi_{95}\left(P_{95}\right)-\chi_{93}\left(P_{95}\right)}$, where $\chi_{s}\left(P_{t}\right)$ reflects the simulated EITC credit based on the schedule from year $s$ and pre-tax income reported for year $t$. Extrapolating based on the median ratio implies that a $\$ 1$ increase in current EITC income translates into a $\$ 3.88$ increase in EITC income over the next five years. 


\section{Conclusion}

Understanding the consequences of growing up poor for a child's well-being is an important research question, but one that is difficult to answer due to the potential endogeneity of family income. The question is particularly interesting to policymakers, since part of the explicit rationale for income support programs (such as the EITC) is to improve the lot of children. Past estimates of the effect of family income on child development have often been plagued by omitted variable bias. That is, children growing up in poor families are likely to have home environments or face other challenges which would continue to affect development even if family income rose substantially.

In this paper, we use an IV strategy to estimate the causal effect of income on children's math and reading achievement. Using a panel of 4,412 children matched to their mothers allows us to address problems associated with both unobserved heterogeneity and endogenous transitory income shocks. Our IV approach exploits the large non-linear changes in the EITC in the late 1980s and 1990s as an exogenous source of variation in family income levels. The largest of these EITC changes doubled benefit amounts for some families between 1993 and 1997, accounting for as much as $\$ 2,100$ in extra income (measured in year $2000 \$$ ). Over the time period in our sample, the EITC expansions raised average family income by more than $10 \%$ for EITC eligible families with two or more children.

We find that extra family income has a modest, but encouraging, causal effect for children growing up in poor families. Our IV results indicate that current income has significant effects on a child's math and reading test scores. The baseline estimates imply that a $\$ 1,000$ increase in income raises contemporaneous math and reading test scores by $6 \%$ of a standard deviation. Over the entire sample period (1987-1999), the median EITC payment for eligible two-child families increased by $\$ 1,670$ (in year $2000 \$$ ), implying an average test score increase of $10 \%$ of a standard deviation for this group.

Our estimates also suggest that the effects are larger for children growing up in more disadvantaged families, younger children, and boys. The results are robust to a variety of alternative specifications, including regressions which account for time-varying state policies, general control functions, and maternal labor market participation. Simple dynamic models suggest that contemporaneous income has the largest effect on achievement, with small effects from past income. An interesting avenue for future research would be to explore why income has modest contemporaneous effects but small long-run effects on achievement. 


\section{References}

[1] A. Attanasio and V. Lechene. Tests of Income Pooling in Household Decisions. Review of Economic Dynamics, 5:720-748, 2002.

[2] L. Barrow and L. McGranahan. The Effects of the Earned Income Credit on the Seasonality of Household Expenditures. National Tax Journal, 53(4):1211-1243, 2000.

[3] S. Black, P. Devereux, and K. Salvanes. Why the Apple Doesn't Fall Far: Understanding Intergenerational Transmission of Human Capital. The American Economic Review, 95(1):43749, 2005.

[4] D. Blau. The Effect of Income on Child Development. Review of Economics and Statistics, 81(2):261-276, May 1999.

[5] R. Blundell, A. Duncan, and C. Meghir. Estimating Labor Supply Responses Using Tax Reforms. Econometrica, 66:827-61, 1998.

[6] Center on Budget and Policy Priorities. The 2005 Earned Income Tax Credit Outreach Kit. Washington, D.C., 2005.

[7] Child Trends and Center for Child Health Research. Early Child Development in Social Context. New York, 2004.

[8] G. Dahl and L Lochner. The Impact of Family Income on Child Achievement. NBER Working Paper No. 11279, 2005.

[9] G. Duncan and J. Brooks-Gunn. Consequences of Growing Up Poor. Russell Sage Foundation, New York, 1997.

[10] G. Duncan, P. Morris, and C. Rodrigues. Does Money Really Matter? Estimating Impacts of Family Income on Young Children's Achievement with Data from Random-Assignment Experiments. Working Paper, 2007.

[11] G. Duncan, W. Yeung, J. Brooks-Gunn, and J. Smith. How Much Does Childhood Poverty Affect the Life Chances of Children? American Sociological Review, 63:406-423, June 1998.

[12] N. Eissa and H. Hoynes. Behavioral Responses to Taxes: Lessons from the EITC and Labor Supply. Tax Policy and the Economy, 20:74-110, 2005.

[13] N. Eissa and H. Hoynes. The Hours of Work Response of Married Couples: Taxes and the Earned Income Tax Credit. In J. Agell and P.B. Sorensen, editors, Tax Policy and Labor Market Performance, pages 187-228. MIT Press, 2006.

[14] D. Feenberg and E. Coutts. An Introduction to the TAXSIM Model. Journal of Policy Analysis and Management, 12(1):189-94, 1993. 
[15] A. Goodman-Bacon and L. McGranahan. How do EITC Recipients Spend their Refunds? Economic Perspectives, 2Q:17-32, 2008.

[16] E. Hanushek and M. Raymond. Does School Accountability Lead to Improved Student Performance? Journal of Policy Analysis and Management, 24(2):297-327, 2005.

[17] R. Haveman and B. Wolfe. The Determinants of Children's Attainments: A Review of Methods and Findings. Journal of Economic Literature, 33(4):1829-1878, Dec. 1995.

[18] J.J. Heckman and E. Vytlacil. Instrumental Variables Methods for the Correlated Random Coefficient Model: Estimating the Average Rate of Return to Schooling when the Return is Correlated with Schooling. Journal of Human Resources, 33(4):974-87, 1998.

[19] V. J. Hotz and J. K. Scholz. The Earned Income Tax Credit. In R. Moffit, editor, Means-Tested Transfer Programs in the U.S. The University of Chicago Press, Chicago, 2003.

[20] G. Imbens and J. Angrist. Identification and Estimation of Local Average Treatment Effects. Econometrica, 62(2):467-75, 1994.

[21] Internal Revenue Service. Participation in the Earned Income Tax Credit Program for Tax Year 1996. Washington, D.C., 2002.

[22] B. Jacob, L. Lefgren, and D. Sims. The Persistence of Teacher-Induced Learning Gains. NBER Working Paper No. 14065, 2008.

[23] D. Levy and G. Duncan. Using Sibling Samples to Assess the Effect of Childhood Family Income on Completed Schooling. Working Paper, 1999.

[24] J. R. Lockwood, D. McCaffrey, L. Mariano, and C. Setodji. Bayesian Methods for Scalable Multivariate Value-Added Assessment. Journal of Educational and Behavioral Satistics, 32(2):125-50, June 2007.

[25] K. Løken. Family Income and Children's Education: Using the Norwegian Oil Boom as a Natural Experiment. Labour Economics, 17(1):118-29, 2010.

[26] K. Løken, M. Mogstad, and M. Wiswall. What Linear Estimators Miss: Re-Examining the Effects of Family Income on Child Outcomes. Working Paper, May 2010.

[27] S. J. Lundberg, R. A. Pollak, and T. J. Wales. Do Husbands and Wives Pool Their Resources? Evidence from the United Kingdom Child Benefit. The Jounal of Human Resources, 32(3):463480, 1997.

[28] S. Mayer. What Money Can't Buy: Family Income and Children's Life Chances. Harvard University Press, Cambridge, 1997.

[29] V. McLoyd. The Impact of Economic Hardship on Black Families and Children: Psychological Distress, Parenting and Socioemotional Development. Child Development, 61:311-46, 1990. 
[30] A. Miller and L. Zhang. The Effects of Welfare Reform on the Academic Performance of Children in Low-Income Households. Working Paper, 2008.

[31] K. Milligan and M. Stabile. Do Child Tax Benefits Affect the Wellbeing of Children? Evidence from Canadian Child Benefit Expansions. Working Paper, December 2009.

[32] P. Oreopoulos, M. Page, and A. Stevens. The Intergenerational Effects of Compulsory Schooling. Journal of Labor Economics, 24(4):729-60, 2006.

[33] P. Oreopoulos, M. Page, and A. Stevens. The Intergenerational Effects of Worker Displacement. Journal of Labor Economics, 26(3):455-83, 2008.

[34] F. Parker, A. Boak, K. Griffin, C. Ripple, and L. Peay. Parent-Child Relationship, Home Learning Environment, and School Readiness. School Psychology Review, 28(3):413-25, 1999.

[35] J. Rothstein. Teacher Quality in Educational Production: Tracking, Decay, and Student Achievement. Working Paper, 2008.

[36] J. K. Scholz. The Earned Income Tax Credit: Participation, Compliance, and Anti-Poverty Effectiveness. National Tax Journal, 47(1):59-81, 1994.

[37] P. Todd and K. Wolpin. On the Specification and Estimation of the Production Function for Cognitive Achievement. Economic Journal, 113(485):3-33, 2003.

[38] P. Todd and K. Wolpin. The Production of Cognitive Achievement in Children: Home, School, and Racial Test Score Gaps. Jounal of Human Capital, 1(1):91-136, 2007.

[39] U.S. Census Bureau, Current Population Reports, Series P60. Poverty in the United States: 2003. U.S. Government Printing Office, Washington, DC, 2004.

[40] J. Ward-Batts. Out of the Wallet and into the Purse. Using Micro Data to Test Income Pooling. The Jounal of Human Resources, 43(2):325-351, 2008.

[41] J. Wooldridge. On Two Stage Least Squares Estimation of the Average Treatment Effect in a Random Coefficient Model. Economics Letters, 56(2):129-33, 1997. 


\section{Appendix: Methodological Issues}

\section{Details on EITC, Tax, and Net Total Income Measures}

We create three family income categories based on the many income components in the NLSY: earned income, unearned income, and non-taxable income. Earned income includes income from wages and salary. Unearned income includes reported income from a business or farm, unemployment compensation, and a residual catch-all question referring to interest income, social security payments, net rental income, and income from other regular sources. Non-taxable income includes income from veteran benefits, worker compensation or disability payments, welfare payments (including food stamps, Supplementary Security Income, or other public assistance), and child support. All of these measures include income received by the mother as well as her spouse. (Income from unmarried partners is not included.)

To calculate actual EITC and tax amounts, we use both earned and unearned income, running them through TAXSIM for the appropriate year. ${ }^{23}$ These are added (EITC) to and subtracted (taxes) from pre-tax/EITC income to create our measure of total net family income, $I_{i a}$. For our sample period, federal EITC schedules only depend on whether there is one or more child in the household. Other taxes depend on the number of children and marital status. We include state taxes and transfers when constructing total family income. Excluding state EITC payments from the instrument has little effect on the estimates, since there are few states with EITC programs during our sample period.

To calculate predicted EITC amounts for use in our instruments, we only input earned income (or predicted earned income) into TAXSIM. We do this because unearned income amounts are generally quite low (and noisy) for persons otherwise qualifying for the EITC, and including unearned income would require the inclusion of a more complicated control function used in IV that depended on both earned and unearned income. The analysis is greatly simplified by leaving unearned income out, with little sacrificed in terms of identifying power.

\section{Estimation of the Contemporaneous Effects Model}

To understand the implicit assumptions underlying our IV strategy, begin by assuming that $\alpha=$ $\beta=0$ in equation (3). In this case, IV will provide consistent estimates if

$$
E_{a}\left[\Delta \varepsilon_{i a} \mid P_{i, a-1}, \Delta \chi_{a}^{I V}\right]=\Phi\left(P_{i, a-1}\right) .
$$

The $a$ subscript on the expectation on the left reflects that it is taken with respect to the age $a$ conditional distribution of $\Delta \varepsilon_{i a}$. The key assumptions underlying this approach are (i) the control function $\Phi(\cdot)$ is flexible enough to capture the true expected relationship between child development shocks and pre-tax income, and (ii) the stability of that relationship over time.

First, notice that $E_{a}\left[\Delta \varepsilon_{i a} \mid P_{i, a-1}, \Delta \chi_{a}^{I V}\left(P_{i, a-1}\right)\right]=E_{a}\left[\Delta \varepsilon_{i a} \mid P_{i, a-1}\right]$ if factors affecting the EITC schedule, $s_{i a}$, do not affect the relationship between shocks to child outcomes and pre-tax income. If

\footnotetext{
${ }^{23}$ While in later years persons with 'excessive' interest and dividend income (above $\$ 2,200-2,500$ depending on the year) should be disqualified from the EITC, we are unable to separate this source of income from social security payments, rental income or other regular sources of income. We effectively ignore this feature of the EITC rules.
} 
everyone was on the same schedule, this would be trivially satisfied since $\Delta \chi_{a}^{I V}$ would only be a function of pre-tax income. Endogeneity problems can be traced to the relationship between $\Delta \varepsilon_{i a}$ and $\left(P_{i, a-1}, P_{i a}\right)$. Stability of this relationship over time (i.e. $E_{a}\left(\Delta \varepsilon_{i a} \mid P_{i, a-1}, P_{i a}\right)=E\left(\Delta \varepsilon_{i a} \mid P_{i, a-1}, P_{i a}\right)$ so the expectation no longer depends on age, $a)$ and stationarity of the income evolution process (i.e. the joint distribution $g\left(P_{i, a-1}, P_{i a}\right)=g\left(P_{i, a^{\prime}-1}, P_{i a^{\prime}}\right)$ for all $\left.a, a^{\prime}\right)$ further implies that $E_{a}\left[\Delta \varepsilon_{i a} \mid P_{i, a-1}\right]=E\left[\Delta \varepsilon_{i a} \mid P_{i, a-1}\right]=\Phi\left(P_{i, a-1}\right)$ for a sufficiently flexible function $\Phi(\cdot)$. Note there is nothing inherently special regarding the use of lagged pre-tax income in this approach; one could reverse the roles played by current and lagged pre-tax income and include a flexible function of current income as the control function.

More generally, when $\alpha$ and $\beta$ are not zero, one can incorporate $x_{i}$ and $\Delta w_{i a}$ into the control function. The estimates would then be consistent if

$$
E_{a}\left[\Delta \varepsilon_{i a} \mid x_{i}, \Delta w_{i a}, P_{i, a-1}, \Delta \chi_{a}^{I V}\right]=\Phi\left(x_{i}, \Delta w_{i a}, P_{i, a-1}\right) .
$$

Estimating such a general control function can be empirically difficult due to the curse of dimensionality. Most of our regressors are indicator variables. In practice, we explore control functions with high order polynomials in $P_{i, a-1}$ and interactions of those polynomials with all of our regressors. In general, the inclusion of interaction terms has negligible effects on estimates of our parameters of interest, and the simpler $\Phi\left(P_{i, a-1}\right)$ is sufficient.

\section{Estimation of Models with Lasting Income Effects}

Estimating more general first-difference models with lagged changes in income like equation (2) requires additional instruments for each new income term. We use instruments analogous to those described above. For example, when we estimate equation (2) using IV, we use $\chi_{a-\ell}^{s_{i, a-1}}\left(\hat{E}\left[P_{i, a-\ell} \mid P_{i, a-1}\right]\right)-$ $\chi_{a-\ell-1}^{s_{i, a-1}}\left(\hat{E}\left[P_{i, a-\ell-1} \mid P_{i, a-1}\right]\right)$ as an instrument for $\Delta I_{i, a-\ell}$. It is still necessary to include the control function $\Phi\left(P_{i, a-1}\right)$, and the assumptions discussed above must still be satisfied. Notice, all simulated EITC changes are based on the schedule and pre-tax income level as of age $a-1$. This maintains tractability, since it does not require inclusion of other lagged values of pre-tax income in the control function $\Phi\left(P_{i, a-1}\right)$. Using different lags of pre-tax income to simulate EITC changes for each lag (e.g. using $\chi_{a-\ell}^{s_{i, a-1}}\left(\hat{E}\left[P_{i, a-\ell} \mid P_{i, a-\ell-1}\right]\right)-\chi_{a-\ell-1}^{s_{i, a-1}}\left(P_{i, a-\ell-1}\right)$ as an instrument for $\left.\Delta I_{i, a-\ell}\right)$ would require including each year of lagged pre-tax income levels (used to create the instruments) in the control function.

\section{Estimating Equations using Two-Year Differences}

Our data only contain measures of child outcomes every other year; however, our model of child outcomes (equation (1)) is based on annual income. We assume (1) describes child outcomes; however, we estimate our models using two-period differences. If we define $\Delta_{2}$ to be the two-period difference operator (e.g. $\Delta_{2} y_{i a}=y_{i a}-y_{i, a-2}$ ), then our model implies:

$$
\Delta_{2} y_{i a}=x_{i}^{\prime} \alpha+\Delta_{2} w_{i a}^{\prime} \beta+\Delta_{2} I_{i a} \delta_{0}+\Delta_{2} I_{i, a-1} \delta_{1}+\ldots+\Delta_{2} I_{i, a-L} \delta_{L}+\Delta_{2} \varepsilon_{i a} .
$$


We estimate versions of this equation for $L=0,1,2$. While estimation of the 'contemporaneous effects' model (i.e. $L=0$ ) does not require income data for years in-between when child outcome measures are observed, estimation of other models does. 
Figure 1a: Federal EITC Schedules for Families with Two or More Children (Year 2000 Dollars)

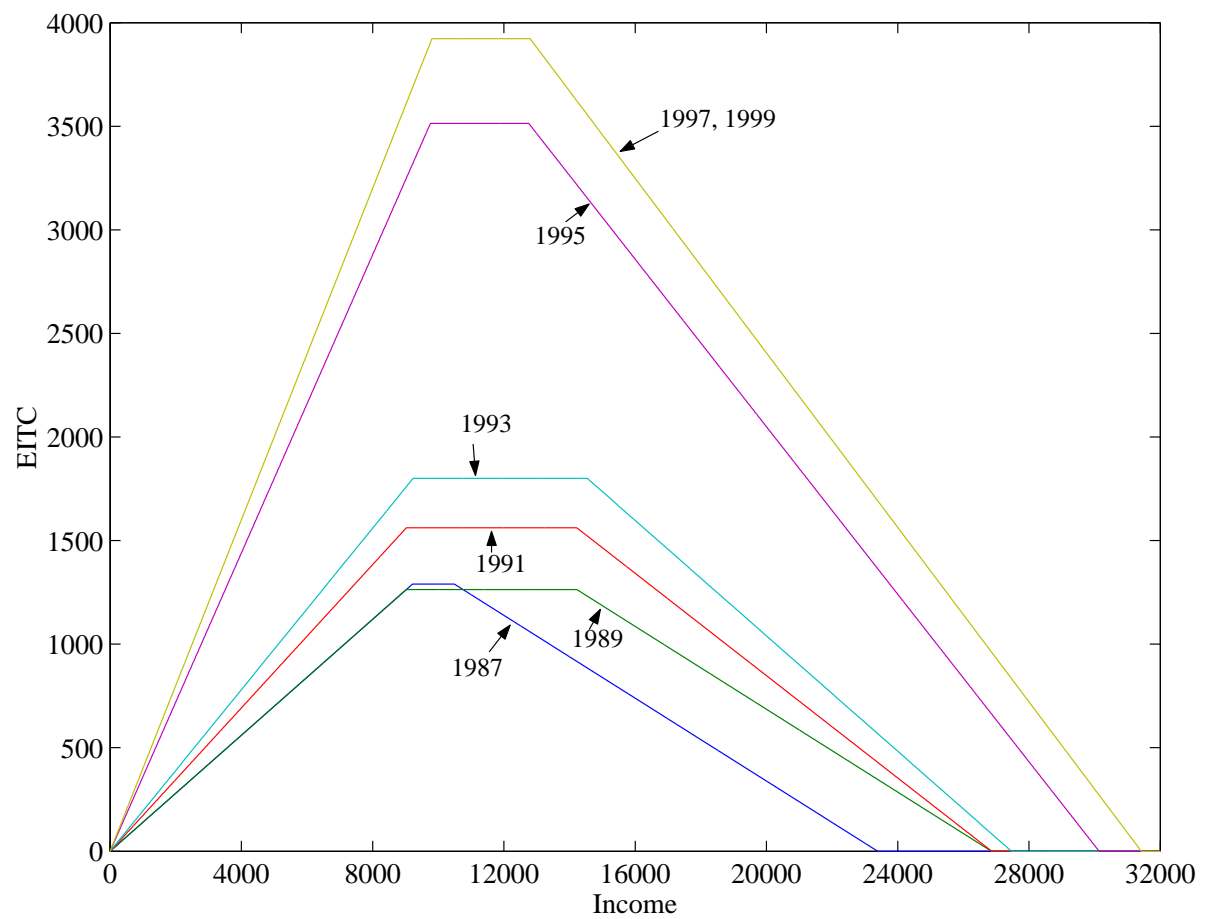

Figure 1b: Two-Year Changes in EITC Schedules for Families with Two or More Children (Year 2000 Dollars)

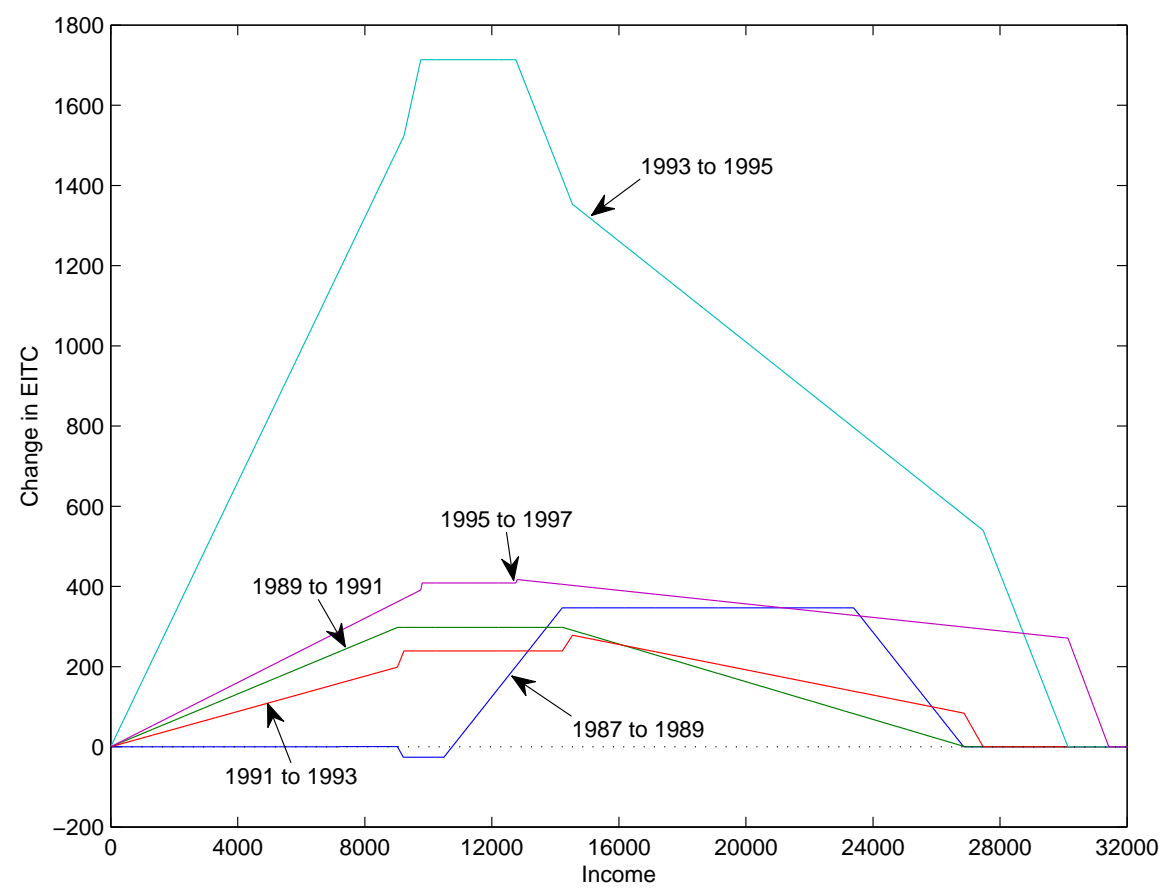


Table 1. Family Income, EITC Eligibility, and EITC Payments over Time (in Year $2000 \$$ )

\begin{tabular}{|c|c|c|c|c|c|c|}
\hline \multirow[b]{2}{*}{$\begin{array}{c}\text { Year } \\
\text { (i) }\end{array}$} & \multirow[b]{2}{*}{$\begin{array}{l}\text { Number of } \\
\text { Children } \\
\text { (ii) }\end{array}$} & \multirow[b]{2}{*}{$\begin{array}{c}\text { Median Lagged } \\
\text { Family Income } \\
\text { (iii) }\end{array}$} & \multirow{2}{*}{$\begin{array}{c}\text { Fraction of } \\
\text { Children } \\
\text { in EITC } \\
\text { Eligible } \\
\text { Families } \\
\text { (iv) }\end{array}$} & \multirow{2}{*}{$\begin{array}{c}\text { Median EITC } \\
\text { Payment } \\
\text { (if Eligible) } \\
(\mathrm{v})\end{array}$} & \multicolumn{2}{|c|}{$\begin{array}{l}\text { EITC Payment as a } \\
\text { Fraction of Family } \\
\text { Income (if Eligible) }\end{array}$} \\
\hline & & & & & $\begin{array}{c}1 \text { Child } \\
\text { Families } \\
\text { (vi) }\end{array}$ & $\begin{array}{l}2+\text { Child } \\
\text { Families } \\
\text { (vii) }\end{array}$ \\
\hline 1988 & 1,187 & 23,463 & 0.31 & 547 & 0.05 & 0.05 \\
\hline 1990 & 1,187 & 24,858 & 0.35 & 718 & 0.05 & 0.05 \\
\hline 1992 & 1,648 & 26,852 & 0.31 & 833 & 0.06 & 0.06 \\
\hline 1994 & 1,655 & 28,832 & 0.35 & 1,124 & 0.09 & 0.07 \\
\hline 1996 & 1,682 & 34,988 & 0.34 & 1,917 & 0.10 & 0.13 \\
\hline 1998 & 1,349 & 38,179 & 0.34 & 2,035 & 0.11 & 0.15 \\
\hline 2000 & 1,088 & 38,390 & 0.34 & 2,226 & 0.11 & 0.16 \\
\hline All & 9,796 & 30,501 & 0.34 & 1,129 & 0.08 & 0.10 \\
\hline
\end{tabular}

Notes: Data are from the Children of the NLSY linked to their mothers in the main NLSY79. The unit of observation is a child. The sample is restricted to those used in our baseline IV analysis in Table 3. Children must have valid math and reading PIAT scores, child control measures in panel A of Table A1, and family income measures for the reported year. Children must also have at least two years of valid observations to be included. Year in column (i) refers to the NLSY survey year; income and EITC payment variables refer to the previous year's income. Family income includes tax payments and tax credits (including the EITC); the sources for family income include earned income, unearned income, and non-taxable income. 
Table 2: OLS Estimates of the Effect of Family Income on Math-Reading Achievement

\begin{tabular}{|c|c|c|c|c|}
\hline & (i) & (ii) & (1iii) & (iv) \\
\hline \multicolumn{5}{|l|}{ A. Estimated in Levels } \\
\hline Current Income & $\begin{array}{r}0.0047^{* *} \\
(0.0011)\end{array}$ & $\begin{array}{r}0.0031^{* *} \\
(0.0014)\end{array}$ & $\begin{array}{c}0.0022 \\
(0.0016)\end{array}$ & $\begin{array}{c}0.0023 \\
(0.0015)\end{array}$ \\
\hline Lagged Income (a-1) & & $\begin{array}{c}0.0022 \\
(0.0016)\end{array}$ & $\begin{array}{c}0.0019 \\
(0.0024)\end{array}$ & \\
\hline Lagged Income (a-2) & & & $\begin{array}{c}0.0015 \\
(0.0019)\end{array}$ & \\
\hline Sum of (a-1) and (a-2) Lagged Income & & & & $\begin{array}{r}0.0017^{*} \\
(0.0009)\end{array}$ \\
\hline $\begin{array}{l}\text { Medium-Term Effect of Increasing } \\
\text { Income by } \$ 1,000 / \text { Year for } 3 \text { Years }\end{array}$ & $\begin{array}{r}0.0047^{* *} \\
(0.0011)\end{array}$ & $\begin{array}{c}0.0053^{* *} \\
(0.0013)\end{array}$ & $\begin{array}{r}0.0056^{* *} \\
(0.0015)\end{array}$ & $\begin{array}{l}0.0056^{* *} \\
(0.0015)\end{array}$ \\
\hline \multicolumn{5}{|l|}{ B. Estimated in Differences } \\
\hline Current Income & $\begin{array}{c}0.0011 \\
(0.0007)\end{array}$ & $\begin{array}{l}0.0015^{*} \\
(0.0008)\end{array}$ & $\begin{array}{c}0.0011 \\
(0.0010)\end{array}$ & $\begin{array}{l}0.0016^{*} \\
(0.0009)\end{array}$ \\
\hline Lagged Income (a-1) & & $\begin{array}{c}0.0005 \\
(0.0009)\end{array}$ & $\begin{array}{c}0.0012 \\
(0.0011)\end{array}$ & \\
\hline Lagged Income (a-2) & & & $\begin{array}{l}-0.0007 \\
(0.0009)\end{array}$ & \\
\hline Sum of (a-1) and (a-2) Lagged Income & & & & $\begin{array}{c}0.0001 \\
(0.0005)\end{array}$ \\
\hline $\begin{array}{l}\text { Medium-Term Effect of Increasing } \\
\text { Income by } \$ 1,000 / \text { Year for } 3 \text { Years }\end{array}$ & $\begin{array}{c}0.0010 \\
(0.0007)\end{array}$ & $\begin{array}{c}0.0020^{*} \\
(0.0010)\end{array}$ & $\begin{array}{c}0.0015 \\
(0.0013)\end{array}$ & $\begin{array}{c}0.0018 \\
(0.0013)\end{array}$ \\
\hline Sample Size (for both panels) & 8,609 & 6,543 & 5,019 & 5,019 \\
\hline
\end{tabular}

Notes: Child achievement is a normalized average of math and reading scores. Income is measured in $\$ 1,000$ of year 2000 dollars. Panel A 'levels' regressions (equation 1) control for all variables listed in Appendix Table A1. Panel B 'difference' regressions (equation 2) use two-period differences and control for baseline variables in Panel A of Table A1. Samples include children taking a math or reading PIAT test in the 1988 survey year or later. 'Medium-Term Effect' is given by the sum of current and all estimated lagged income coefficients in columns (i)-(iii) and the sum of the coefficient on current income plus twice the coefficient on the sum of lagged income measures in column (iv). Standard errors are reported in parentheses and are clustered at the family level. ${ }^{* *}$ Significant at the $5 \%$ level, * significant at the $10 \%$ level. 
Table 3: Baseline IV Estimates of 'Contemporaneous Effects' Model

\begin{tabular}{lcccc}
\hline \hline & $\begin{array}{c}\text { Combined Math } \\
\text { and Reading } \\
\text { (i) }\end{array}$ & $\begin{array}{c}\text { Reading } \\
\text { Recognition } \\
\text { (ii) }\end{array}$ & $\begin{array}{c}\text { Reading } \\
\text { Comprehension } \\
\text { (iii) }\end{array}$ & $\begin{array}{c}\text { Math } \\
\text { (iv) }\end{array}$ \\
\hline & & & & \\
Current Income & $0.0610^{* *}$ & $0.0359^{*}$ & $0.0613^{* *}$ & $0.0582^{* *}$ \\
& $(0.0231)$ & $(0.0195)$ & $(0.0273)$ & $(0.0273)$ \\
$1^{\text {st }}$ Stage Coeff. on Instrument & $1.270^{* *}$ & $1.270^{* *}$ & $1.270^{* *}$ & $1.270^{* *}$ \\
& $(0.381)$ & $(0.381)$ & $(0.381)$ & $(0.381)$ \\
\end{tabular}

Notes: Income is measured in $\$ 1,000$ of year 2000 dollars. All specifications control for 'baseline variables' listed in Appendix Table A1, an indicator for positive lagged pre-tax income, and a fifth order polynomial in lagged pre-tax income. All models are estimated in two-year differences to account for unobserved child fixed effects. See the Online Appendix for all other first- and secondstage coefficient estimates. Sample size is 8,609 for all the columns. Standard errors are reported in parentheses and are clustered at the family level. ${ }^{* *}$ Significant at the $5 \%$ level, ${ }^{*}$ significant at the $10 \%$ level. 
Table 4: IV Estimates of 'Contemporaneous Effects' Model Accounting for Time Trends and Time-Varying State Policies (Math-Reading Achievement)

\begin{tabular}{lcc}
\hline \hline & $\begin{array}{c}\text { Effect of Current } \\
\text { Income }\end{array}$ & $\begin{array}{c}1^{s t} \text { Stage Coeff. } \\
\text { on Instrument }\end{array}$ \\
\hline A. Year Dummies & $0.0694^{*}$ & $0.745^{* *}$ \\
& $(0.0390)$ & $(0.348)$ \\
B. Linear Time Trend & $0.0863^{* *}$ & $0.847^{* *}$ \\
& $(0.0379)$ & $(0.334)$ \\
C. Linear Time Trend Interacted with Control Function & $0.0805^{* *}$ & $1.115^{* *}$ \\
& $(0.0399)$ & $(0.485)$ \\
D. State School Accountability Policies Interacted with & $0.0533^{* *}$ & $1.299^{* *}$ \\
$\quad$ Control Function & $(0.0221)$ & $(0.406)$ \\
E. State Welfare Policies Interacted with Control Function & $0.0670^{* *}$ & $1.311^{* *}$ \\
& $(0.0268)$ & $(0.436)$ \\
F. Time Trend, Accountability and Welfare Policies & $0.0630^{*}$ & $1.193^{* *}$ \\
$\quad$ Interacted with Control Function & $(0.0338)$ & $(0.513)$ \\
\hline \hline
\end{tabular}

Notes: Child achievement is a normalized average of math and reading scores. Income is measured in $\$ 1,000$ of year 2000 dollars. All specifications control for 'baseline variables' listed in Appendix Table A1. All specifications are estimated in two-year differences to account for unobserved child fixed effects. Sample size is 8,609 for all specifications. Standard errors are reported in parentheses and are clustered at the family level. ${ }^{* *}$ Significant at the $5 \%$ level, ${ }^{*}$ significant at the $10 \%$ level. 
Table 5: IV Estimates of Achievement Models with Lasting Income Effects

\begin{tabular}{lccc}
\hline \hline & (i) & (ii) & (iii) \\
\hline & & & \\
Current Income & $0.0436^{*}$ & 0.0551 & $0.0515^{* *}$ \\
& $(0.0236)$ & $(0.0478)$ & $(0.0226)$ \\
Lagged Income (a-1) & 0.0216 & 0.0135 & \\
& $(0.0408)$ & $(0.0733)$ & \\
Lagged Income (a-2) & & 0.0206 & \\
& & $(0.0381)$ & 0.0186 \\
Sum of (a-1) and (a-2) Lagged Income & & & $(0.0254)$ \\
& & & \\
& $0.0651^{*}$ & 0.0892 & 0.0888 \\
Medium-Term Effect of Increasing & $(0.0349)$ & $(0.0604)$ & $(0.0598)$ \\
Income by $\$ 1,000 / Y e a r$ for 3 Years & & & \\
& $6.17,3.59$ & $3.98,1.39,2.16$ & $5.53,1.77$ \\
F-statistics from 1st Stage & 6,543 & 5,019 & 5,019 \\
Sample Size & & & \\
\hline \hline
\end{tabular}

Notes: Child achievement is a normalized average of math and reading scores. Income is measured in $\$ 1,000$ of year 2000 dollars. All specifications control for 'baseline variables' listed in Appendix Table A1, an indicator for positive lagged pre-tax income, and a fifth order polynomial in lagged pre-tax income. All models are estimated in two-year differences to account for unobserved child fixed effects. 'Medium-Term Effect' is given by the sum of current and all estimated lagged income coefficients in columns (i) and (ii) and the sum of the coefficient on current income plus twice the coefficient on the sum of lagged income measures in column (iii). F-statistics are for tests that all instruments equal zero in first-stage equations. See the Online Appendix for all other first- and second-stage coefficient estimates. Standard errors are reported in parentheses and are clustered at the family level. ${ }^{* *}$ Significant at the $5 \%$ level, ${ }^{*}$ significant at the $10 \%$ level. 
Table 6. IV Estimates of 'Contemporaneous Effects' Model for Various Subgroups

\begin{tabular}{|c|c|c|c|c|c|c|}
\hline & $\begin{array}{l}\text { Mother's } \\
\text { Education }\end{array}$ & Race & $\begin{array}{c}\text { Mother's } \\
\text { Marital } \\
\text { Status }\end{array}$ & $\begin{array}{l}\text { Mother's } \\
\text { AFQT }\end{array}$ & $\begin{array}{l}\text { Child's } \\
\text { Age }\end{array}$ & $\begin{array}{l}\text { Child's } \\
\text { Gender }\end{array}$ \\
\hline & $\begin{array}{l}\text { High School } \\
\text { or Less }\end{array}$ & $\begin{array}{l}\text { Black or } \\
\text { Hispanic } \\
\end{array}$ & $\begin{array}{c}\text { Not } \\
\text { Married } \\
\end{array}$ & $\begin{array}{c}\text { Low } \\
\text { AFQT } \\
\end{array}$ & $\begin{array}{l}\text { Age } \\
\leq 12 \\
\end{array}$ & $\underline{\text { Male }}$ \\
\hline Effect of Current Income & $\begin{array}{c}0.0536^{* *} \\
(0.0211)\end{array}$ & $\begin{array}{c}0.0800^{* *} \\
(0.0304)\end{array}$ & $\begin{array}{l}0.0806^{*} \\
(0.0463)\end{array}$ & $\begin{array}{c}0.0708^{* *} \\
(0.0340)\end{array}$ & $\begin{array}{c}0.0765^{*} \\
(0.0436)\end{array}$ & $\begin{array}{c}0.0879 * * \\
(0.0446)\end{array}$ \\
\hline $\begin{array}{l}1^{\text {st }} \text { Stage Coeff. } \\
\text { on Instrument }\end{array}$ & $\begin{array}{c}1.386^{* *} \\
(0.402)\end{array}$ & $\begin{array}{c}1.281^{* *} \\
(0.428)\end{array}$ & $\begin{array}{c}0.808^{* *} \\
(0.389)\end{array}$ & $\begin{array}{c}1.089^{* *} \\
(0.433)\end{array}$ & $\begin{array}{l}1.050^{* *} \\
(0.495)\end{array}$ & $\begin{array}{c}1.056^{* *} \\
(0.472)\end{array}$ \\
\hline 'Percent in EITC Range' & 56.4 & 62.8 & 90.1 & 64.9 & 46.4 & 49.6 \\
\hline Sample Size & 6,253 & 4,602 & 2,977 & 4,311 & 4,654 & 4,261 \\
\hline Effect of Current Income & $\begin{array}{l}\text { Some College } \\
\text { or More } \\
0.0163 \\
(0.0107)\end{array}$ & $\begin{array}{c}\begin{array}{c}\text { White } \\
\text { (not Hisp.) }\end{array} \\
0.0146 \\
(0.0295)\end{array}$ & $\begin{array}{l}\text { Married } \\
0.0434^{*} \\
(0.0248)\end{array}$ & $\begin{array}{c}\text { High } \\
\text { AFQT } \\
0.0486 \\
(0.0361)\end{array}$ & $\begin{array}{c}\text { Age } \\
\geq 12 \\
0.0516^{* *} \\
(0.0235)\end{array}$ & $\begin{array}{l}\text { Female } \\
0.0399^{*} \\
(0.0221)\end{array}$ \\
\hline $\begin{array}{l}1^{\text {st }} \text { Stage Coeff. } \\
\text { on Instrument }\end{array}$ & $\begin{array}{c}0.086 \\
(1.123)\end{array}$ & $\begin{array}{l}1.265 \\
(0.798)\end{array}$ & $\begin{array}{c}2.153^{* *} \\
(0.907)\end{array}$ & $\begin{array}{l}1.466^{*} \\
(0.802)\end{array}$ & $\begin{array}{c}1.460^{* *} \\
(0.452)\end{array}$ & $\begin{array}{c}1.479^{* *} \\
(0.489)\end{array}$ \\
\hline 'Percent in EITC Range' & 30.8 & 34.1 & 28.0 & 33.3 & 53.0 & 49.3 \\
\hline Sample Size & 2,356 & 4,007 & 5,632 & 4,040 & 3,955 & 4,348 \\
\hline
\end{tabular}

Notes: Income is measured in $\$ 1,000$ of year 2000 dollars. All specifications control for 'baseline variables' listed in Appendix Table A1 and are estimated in two-year differences to account for unobserved child fixed effects. 'Percent in EITC Range' is calculated as the fraction with lagged pre-tax income less than or equal to $\$ 30,000$. Standard errors are reported in parentheses and are clustered at the family level. ${ }^{* *}$ Significant at the $5 \%$ level, ${ }^{*}$ significant at the $10 \%$ level. 
Table 7: Robustness of IV Estimates for 'Contemporaneous Effects' Model

\begin{tabular}{lcc}
\hline \hline & $\begin{array}{c}\text { Effect on } \\
\text { Child Achievement }\end{array}$ & $\begin{array}{c}1^{\text {st }} \text { Stage Coefficient } \\
\text { on Instrument }\end{array}$ \\
\hline A. Additional Control Variables & & $0.936^{* *}$ \\
Effect of Current Income & $0.0799^{* *}$ & $(0.404)$ \\
B. No Control Variables (Except Control Function, i.e., Polynomial in Lagged Earnings) & \\
Effect of Current Income & $0.0657^{* *}$ & $1.318^{* *}$ \\
& $(0.0231)$ & $(0.380)$ \\
C. Interact Control Function with Baseline Regressors & & $1.310^{* *}$ \\
Effect of Current Income & $0.0608^{* *}$ & $(0.384)$ \\
& $(0.0223)$ & $1.186^{* *}$ \\
D. Include State Dummies with Baseline Regressors & & $(0.387)$ \\
Effect of Current Income & $0.0645^{* *}$ & $1.241^{* *}$ \\
& $(0.0258)$ & $(0.477)$ \\
E. Use NLSY-supplied Weights & & \\
Effect of Current Income & $0.0508^{* *}$ & $1.211^{* *}$ \\
& $(0.0259)$ & $(0.298)$ \\
F. Log Family Income Measure & & $0.901^{* *}$ \\
Effect of Log Current Income & $0.6393^{* *}$ & $(0.371)$ \\
G. Controls for Mother's Labor Market Participation and Work Hours & $(0.2169)$ & \\
Effect of Current Income & $0.0841^{* *}$ & $(0.0402)$ \\
Effect of Mother's Participation & -0.0074 & $(0.0456)$ \\
Effect of Mother's Work Hours (in 100's) & $-0.0262^{* *}$ & $(0.0124)$ \\
\hline \hline
\end{tabular}

Notes: Specifications identical to those for 'Combined Math and Reading' in Table 3 with the noted exceptions. Specification A controls for all variables in Appendix Table A1 and state school accountability and welfare policies (in addition to the control function in lagged pre-tax income). Specification B controls only for the control function. Specification $\mathrm{C}$ interacts the control function with all baseline regressors. Specification D includes state indicators along with all baseline regressors. Specification E uses the NLSY-supplied weights for mothers (includes baseline controls and control function). Specification F uses log family income rather than income measured in levels (includes baseline controls and control function). Specification G controls for mother's labor market participation and hours worked in addition to baseline regressors and control function. Sample sizes are 8,609 for Specifications A-F and 8,239 for Specification G. Standard errors are reported in parentheses and are clustered at the family level. ${ }^{* *}$ Significant at the $5 \%$ level, ${ }^{*}$ significant at the $10 \%$ level. 
Table A1: Sample Characteristics for Children, their Mothers, and their Families

\begin{tabular}{|c|c|c|c|c|}
\hline & $\begin{array}{c}\text { Entire } \\
\text { Sample } \\
\text { (i) }\end{array}$ & $\begin{array}{c}\text { Eligible } \\
\text { for EITC } \\
\text { (ii) }\end{array}$ & $\begin{array}{c}\text { Not Eligible } \\
\text { for EITC } \\
\text { (iii) }\end{array}$ & $\begin{array}{l}\text { Difference } \\
\text { (ii)-(iii) } \\
\text { (iv) }\end{array}$ \\
\hline \multicolumn{5}{|l|}{ A. Baseline Variables } \\
\hline male & 0.50 & 0.49 & 0.50 & 0.00 \\
\hline age & 11.00 & 11.23 & 10.88 & $0.35^{* *}$ \\
\hline no siblings & 0.10 & 0.13 & 0.09 & $0.05^{* *}$ \\
\hline one sibling & 0.40 & 0.35 & 0.42 & $-0.07 * *$ \\
\hline two or more siblings & 0.50 & 0.52 & 0.50 & 0.02 \\
\hline black & 0.35 & 0.47 & 0.29 & $0.19^{* *}$ \\
\hline hispanic & 0.19 & 0.20 & 0.19 & 0.01 \\
\hline \multicolumn{5}{|l|}{ B. Additional Variables } \\
\hline mother's age & 33.44 & 33.23 & 33.55 & $-0.32^{* *}$ \\
\hline mother a high school dropout & 0.21 & 0.29 & 0.17 & $0.11^{* *}$ \\
\hline mother a high school graduate & 0.53 & 0.54 & 0.52 & 0.01 \\
\hline mother attended some college & 0.20 & 0.17 & 0.22 & $-0.05^{* *}$ \\
\hline mother graduated college & 0.06 & 0.01 & 0.08 & $-0.07 * *$ \\
\hline mother's AFQT score (normalized \& age adjusted) & -0.47 & -0.77 & -0.32 & $-0.46^{* *}$ \\
\hline mother lived with both natural parents at age 14 & 0.64 & 0.57 & 0.68 & $-0.11^{* *}$ \\
\hline mother's father present in household & 0.03 & 0.05 & 0.02 & $0.03^{* *}$ \\
\hline mother's mother present in household & 0.06 & 0.10 & 0.05 & $0.05^{* *}$ \\
\hline number of adults in household & 1.86 & 1.67 & 1.96 & $-0.29 * *$ \\
\hline highest grade completed by mother's father & 8.42 & 7.35 & 8.96 & $-1.63^{* *}$ \\
\hline highest grade completed by mother's mother & 9.65 & 8.94 & 10.01 & $-1.07 * *$ \\
\hline mother married last year & 0.65 & 0.37 & 0.78 & $-0.41^{* *}$ \\
\hline age of mother's spouse & 35.39 & 35.25 & 35.43 & -0.18 \\
\hline mother's spouse a high school dropout & 0.16 & 0.31 & 0.13 & $0.18^{* *}$ \\
\hline mother's spouse a high school graduate & 0.50 & 0.52 & 0.50 & 0.02 \\
\hline mother's spouse attended some college & 0.20 & 0.14 & 0.21 & $-0.07 * *$ \\
\hline mother's spouse a college graduate & 0.14 & 0.03 & 0.16 & $-0.14^{* *}$ \\
\hline year & 1993 & 1993 & 1993 & 0.13 \\
\hline \multicolumn{5}{|l|}{ missing observation indicators: } \\
\hline mother's AFQT score & 0.03 & 0.02 & 0.03 & $-0.01^{*}$ \\
\hline mother lived with both natural parents at age 14 & 0.00 & 0.01 & 0.00 & $0.00^{*}$ \\
\hline mother's father present in household & 0.00 & 0.00 & 0.00 & 0.00 \\
\hline mother's mother present in household & 0.00 & 0.00 & 0.00 & 0.00 \\
\hline number of adults in household missing & 0.02 & 0.01 & 0.02 & 0.00 \\
\hline highest grade completed by mother's father & 0.08 & 0.10 & 0.07 & $0.03^{* *}$ \\
\hline highest grade completed by mother's mother & 0.03 & 0.03 & 0.02 & 0.00 \\
\hline age of mother's spouse & 0.00 & 0.00 & 0.00 & 0.00 \\
\hline mother's spouse's education & 0.00 & 0.00 & 0.00 & 0.00 \\
\hline number of child-year observations & 9,796 & 3,286 & 6,510 & \\
\hline number of children & 4,412 & 2,019 & 3,249 & \\
\hline
\end{tabular}

Notes: Unit of observation is a child-year, where children and parents can appear repeatedly in the sample. The sample is restricted to observations used in our IV analysis: children must have valid math and reading PIAT scores, child control measures (in panel A), and family income measures in a year to be included. Children must also have at least two years of valid observations to be included. Race of the child is based on the reported race of the mother. Mother's education variables represent completed education when the mother is age 23. Average spousal education and age are reported for the sample of married mothers (sample sizes are 6,334, 1,228 and 5,106 for columns (i), (ii), and (iii), respectively). In column (iv), ** denotes statistical significance at $5 \%$ level, and * denotes statistical significance at $10 \%$ level. 